\title{
Ablative Subduction: A Two-Sided Alternative to the Conventional Subduction Model
}

\author{
Winston C. TaO and Richard J. O'ConNell \\ Department of Earth and Planetary Sciences, Harvard University, Cambridge, Massachusetts
}

\begin{abstract}
Subduction is conventionally modelled as a convergence and overlapping of two semirigid plates; such a convergence is one-sided, in that one lithospheric plate descends while the other remains on the surface. We suggest an alternative model, one based on the dynamics of fluids. In this model, the viscous lower lithosphere flows downward, and the brittle upper lithosphere deforms in passive response. This process is potentially double-sided, for we find that even a buoyant plate can be dragged downward by a dense, descending neighbor. Thus an apparent overriding plate may be worn away by a process of viscous ablation, with the rate of ablation a function of plate buoyancy. We call this process "ablative subduction". Ablative subduction allows us to simply interpret observations concerning slab profiles, interplate seismicity, back arc tectonics, and complex processes such as double subduction and subduction polarity reversal. In performing experiments modelling the evolution of simple, fluid "slabs", we find that slab profile is strongly influenced by ablation in the overriding plate. When ablation is weak, as when a buoyant continent borders the trench, deformable slabs adopt shallow, Andean-style profiles. These profiles develop over time from an initially steep shape. More vigorous ablation rates, as might occur in an oceanocean convergence, yield steeper, Marianas-style profiles. Thus differences between Marianas-style and Andean-style slabs may result from differences in ablation rate and subduction duration. The occurrence of ablation might not be easily detected at depth, because material from subducting and ablating plates adhere closely as a single slab. These slabs show downdip deformations that are consistent with seismic focal mechanisms. Plate deformations associated with ablative subduction are also consistent with observed patterns of seismicity. In particular, the relative aseismicity of Marianas-style plate boundaries is consistent with the ablative model; we may thus explain how plates can converge aseismically, without requiring that these plates be decoupled. Ablation should be weakest in Andean-style subduction, although pulses of rapid ablation might lead to episodes of crustal shortening; in oceanic regions, the manifestation of ablation may depend upon tectonic regime. In an extensional area like the Marianas, ablation may be temporally selflimiting, and ablative cycles may explain conflicting observations of tectonic erosion and accretion. In a compressional regime, vigorous ablation might lead to observations of double subduction and subduction reversal. In each case, the behavior of the lower lithosphere is relatively simple; what varies is the rate of ablation and the response of the upper lithosphere.
\end{abstract}

\section{INTRODUCTION}

Subduction moves material from the surface, where we can see it, into the mantle, where we cannot. Models describing the process must therefore rely on indirect lines of evidence, the implications of which may not be unique. In the standard interpretation, based upon early conceptions of a simple, brittle lithosphere, subduction occurs as a simple, one-sided overlapping of rigid tectonic plates. However, in the absence of direct measurements of relative plate consumption, other interpretations are possible.

In this paper, we examine the plausibility of a two-sided, fluid-based model of lithospheric subduction, one based upon current views of lithospheric structure. Within this model, the viscous lower regions of the lithosphere flow downward as a fluid, with the more brittle upper lithosphere deforming in passive response. The asymmetry of plate consumption is then determined by the asymmetry of plate buoyancy: when differences in lithospheric buoyancy are great, as in a continental region like the Andes, the bulk of the slab is composed primarily of material from the denser plate. But when plate densities on either side of the trench are more symmetric, subduction may in turn be more two-sided. Hence what appears to be an overrid-

\section{Copyright 1992 by the American Geophysical Union.}

Paper number 91JB02422.

0148-0227/92/91JB-02422\$05.00 ing plate may be consumed by a process of viscous ablation. We find that this ablative model of subduction is consistent with major subduction-related observations, that it suggests a simple explanation for why continental and oceanic-style subduction zones differ greatly in observations of slab profile and surface tectonics, and that it may provide a means of interpreting complex tectonic processes such as double subduction and subduction polarity reversal.

\section{Classical Subduction: Assumptions and Problems}

The underlying basis of any subduction model is that lithosphere created at mid-ocean ridges must somehow return to the mantle. Early in the development of modern plate tectonic theory, this recycling was recognized to lie at convergent plate boundaries, where patterns of topography, seismicity, and volcanism suggested the descent of surface material [Benioff, 1954; McKenzie and Parker, 1967; Morgan, 1968; Wilson, 1965; Isacks et al., 1968]. Though the first depictions of this descent show material being removed from both sides of a trench [Holmes, 1944; Wilson, 1963], the one-sided model came into favor by the late 1960s [Isacks et al., 1968; McKenzie and Morgan, 1969; Isacks and Molnar, 1969] and provided an elegant means of relating the inclined profiles of seismic Benioff zones to the presence of nearby continental masses. In the model's simplest form, the buoyancy of a continental plate enables it to override denser oceanic lithosphere; forced downward by the collision, the oceanic plate bends, generates thrust-faulting 
earthquakes as it scrapes past the overriding plate, and sinks along the Benioff zone as a coherent slab. The place where the subducting plate tilts downward is then marked by an oceanic trench, and partial melting of slab material gives rise to volcanism upon the overriding plate. A clear distinction is thus made between overriding and subducting plates, with the disposition of continental crust determining which plate will override; where ocean meets ocean, the presence of island arc material likewise serves to define the overriding plate. Hence the classical model ties together arc volcanism, oceanic trenches, interplate seismicity, and seismic Benioff zones, relating them all to the downward bending of a dense, semirigid plate beneath a buoyant continent or island arc.

However, while the classical model may be used to interpret the most important aspects of subduction, we sometimes have difficulty in applying it to details of slab and plate dynamics. A notable difficulty concerns the many differences observed between continental and oceanic-style subduction zones (Figure 1): typically, oceanic zones of the Marianas type show steep, deep slabs and tensional tectonics in the back arc region, while continental, Andean-style areas contain extremely shallow slabs which underthrust hundreds of kilometers of horizontally compressed continent [Uyeda and Kanamori, 1979; Jarrard, 1986]. As the classical model makes no fundamental distinction between continentocean and ocean-ocean convergence (irrespective of overriding plate type, subduction should be but a simple passing of one plate beneath another), we must ascribe these differences to such secondary characteristics as absolute plate velocities, relative convergence velocities, or densities of the subducted plates [Cross and Pilger, 1982; Chase, 1978]. For specific subduction zones, one or more of these mechanisms can well apply on a case by case basis; however, the overall differences between the two classes are so systematic as to suggest a more basic difference in dynamics, one based on the character of the overriding plate.

Further problems arise in relating the dynamics of simple plates to the dynamics of a layered lithosphere. It is currently thought that the lower portion of the lithosphere behaves as a fluid over geologic time scales [Parsons and McKenzie, 1978]. Such a rheology will inhibit subduction asymmetry: with uniformly solid plates, one plate might well slide completely over another; but if the lithosphere is layered, the top of a descending plate should shear the viscous regions of its neighbor. This shear will tend to carry material from the overriding plate downward. If the overriding plate is continental, crustal buoyancy might minimize the subsequent loss of material; but if the plate is oceanic, then loss rates could perhaps be appreciable. For example, we note that landmasses in western Pacific subduction zones are typically sparse, appearing only as narrow island chains lining one side of the trench; without great buoyant masses to preserve them, the overriding plates in such regions might be significantly ablated.

\section{One-Sided Subduction}

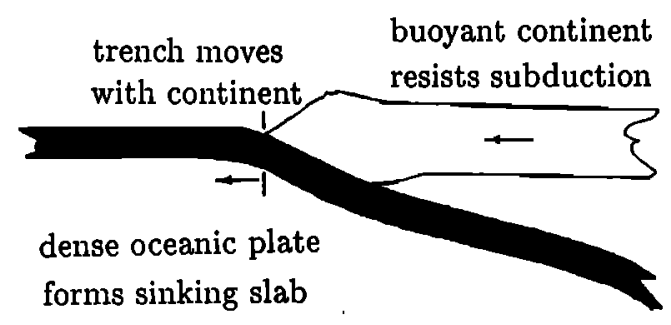

\section{Ablative Subduction}

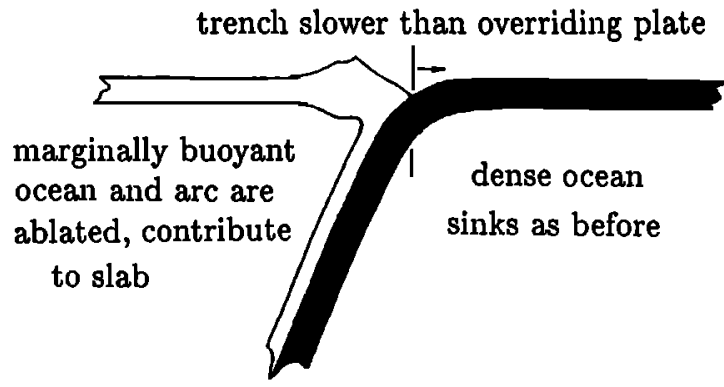

Fig. 1a. One-sided versus two-sided (ablative) subduction models.
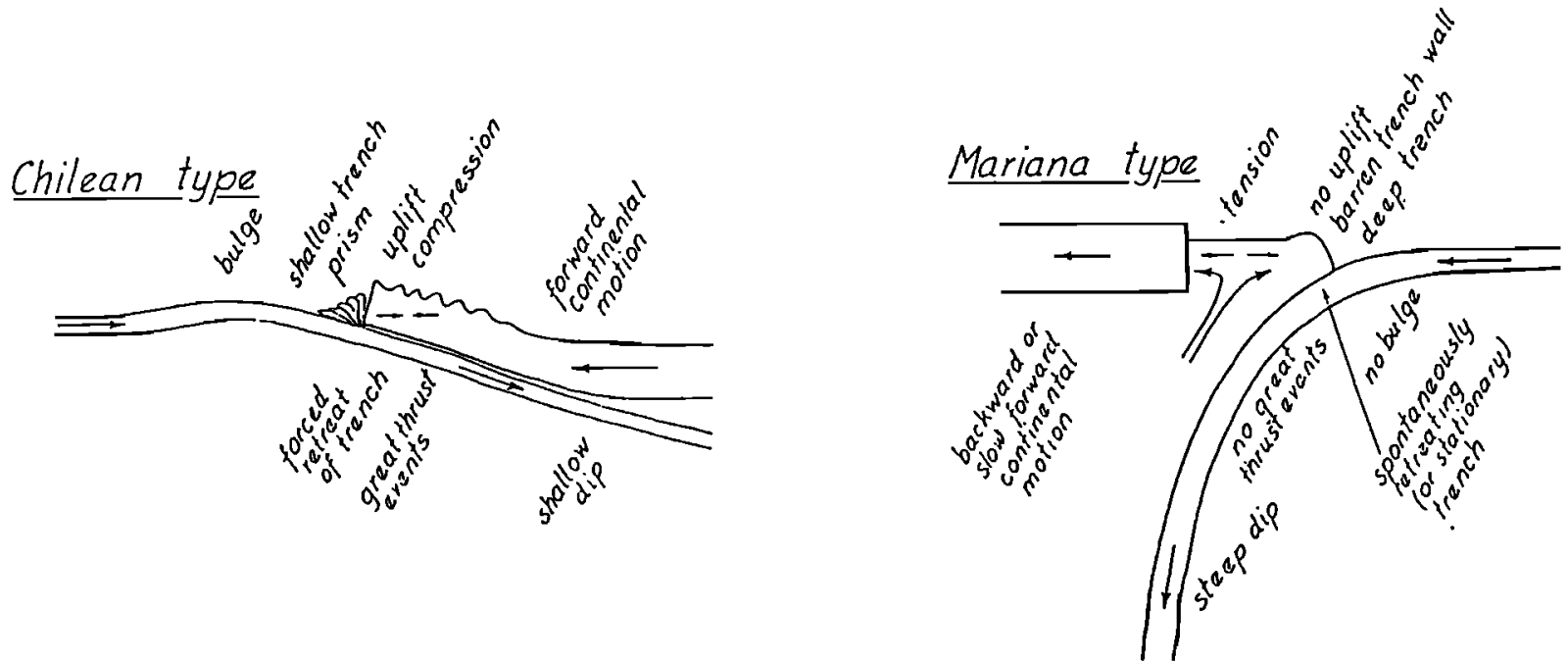

Fig. 1b. Continental and oceanic subduction endmembers [from Uyeda and Kanamori, 1979]. 
That ablative losses may be possible is suggested by laboratory and numerical models of mantle convection: thermal downwellings in homogeneous Newtonian fluids are invariably two-sided [Malkus and Veronis, 1958; Chandrasekhar, 1961; Olson, 1984], as the descent of material on one side of a trench tends to drag along material from the other side; once thus entrained, even buoyant material may adhere to a sinking slab and descend to great depths [Richards and Davies, 1989]. To remove this effect and produce one-sided downwellings, slip zones have been introduced at the trench to mimic the effect of stress-dependent rheologies; to fully decouple the plates, these slip zones must stretch from the Earth's surface to the base of the lithosphere [Kincaid and Olson, 1987] or extend still deeper into the mantle [Gurnis and Hager, 1988]. Even after the insertion of such heterogeneities, dense overriding plates still often sink, and further constraints are required to keep them at the surface [Gurnis and Hager, 1988]. While future experiments using more sophisticated rheologies may yet produce perfect subduction asymmetry, the strong tendency for two-sided subduction to occur in physical and numerical simulations suggests its occurrence in nature as well.

Even assuming that complete subduction asymmetry is somehow maintained in all subduction zones, there are difficulties of interpretation in complex oceanic regions. A straightforward application of the rigid plate model often gives rise to unusual slab configurations (Figure 2), and further complications arise in trying to explain time-dependent changes in subduction geometry. Particularly troublesome is the issue of subduction polarity reversal. In order for a classical subduction zone to change direction, subduction must halt (perhaps in response to an arc-arc collision), the
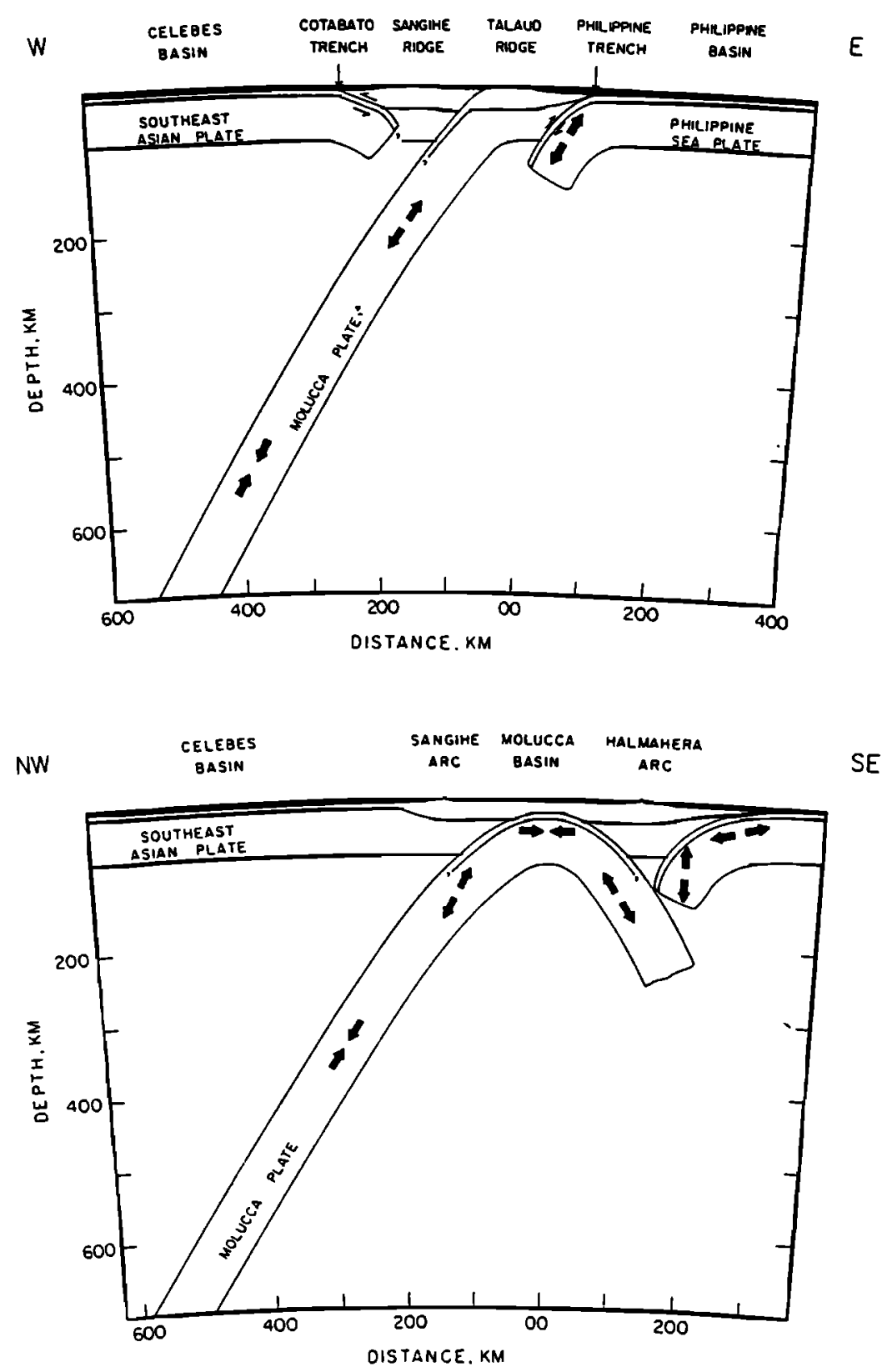

Fig. 2. Complex applications of the classical subduction model. Proposed slab profiles south of Mindanao, Philippines [from Cardwell et al., 1980]. 
slab must detach from the formerly subducting plate, and subduction must reinitiate on the opposite side of the arc (Figure 3). Each of these steps is problematic. That subduction might not be easily halted is suggested by the longevity of continental subduction zones (over 200 m.y. duration in the case of Peru-Chile [Jarrard, 1986]) and by the restricted subduction of a buoyant continental margin that is apparently occurring north of the Philippines [Hamburger et al., 1980]. Moreover, in applying the classical model, we assume that the upper lithosphere is strong enough to control overall plate dynamics; this strength should hinder both subduction reinitiation and the detaching of a slab from a formerly subducting plate. For these reasons, we would expect subduction reversal to be an extremely unusual event. On the contrary, however, reversals of slab polarity appear to be rather common. They have been proposed in the New Hebrides [Carney and MacFarlane, 1982], New Britain [Page and Ryburn, 1977], Solomon Islands [Karig and Mamm-

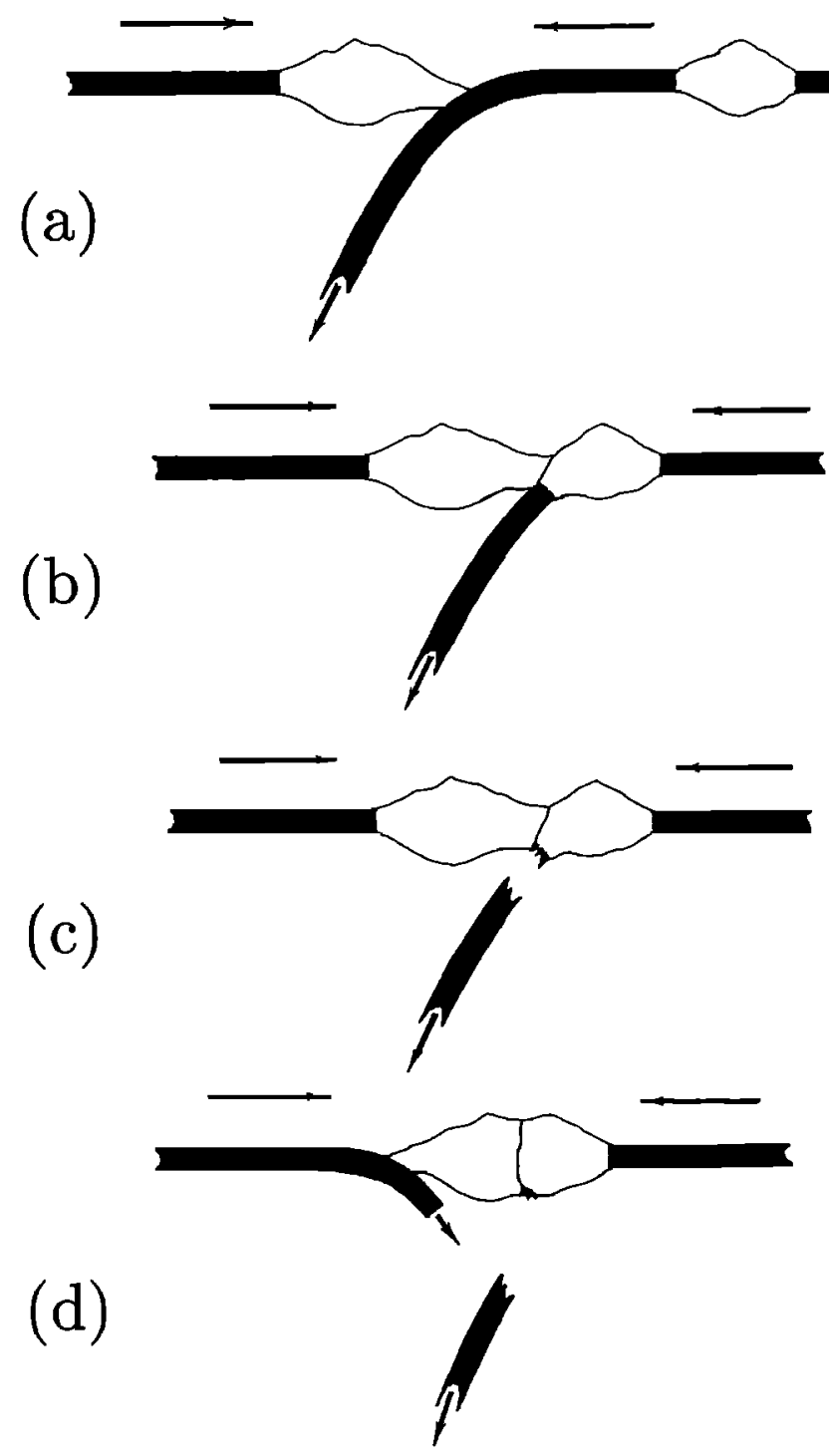

Fig. 3. Classical mechanism for slab reversal. (a) and (b) When buoyant masses (e.g., island arcs) collide, subduction at the original trench is halted. (c) The slab detaches from the old subducting plate, and (d) subduction reinitiates on the opposite side of the enlarged island arc. erickx, 1972], North Sulawesi, which is ongoing and progressing toward the Sangihe Arc [Hamilton, 1979; Silver et al., 1983], and Halmahera [Hamilton, 1979; Cardwell et al., 1980]. The Philippine region in general seems to have had west dipping subduction in the Paleogene and east dipping in the latter Neogene, and is currently undergoing a northward progressive shift back to west dipping subduction [Lewis and Hayes, 1980; Divis, 1980]. Moreover, at least one of these reversals, beneath Luzon in the late Oligocene, seems to have occurred without an arc-arc collision or any other apparent cause [Lewis and Hayes, 1980].

\section{Ablative Subduction}

It appears then that the classical subduction model, while elegantly applicable to first-order observations, is not easily extended to details of lithospheric dynamics and complex oceanic tectonics. We therefore ask if one can more simply interpret the subduction process using a different conceptual framework.

We can derive an alternative subduction model by reappraising the dynamical role of the elastic upper lithosphere. In adapting the classical model to modern views of lithospheric rheology, we implicitly assume that the lithosphere is so dominated by the strength of its uppermost layers that its overall behavior is platelike. This assumption might not be entirely warranted. The concept of plate rigidity primarily concerns the lithosphere's resistance to deformation along a horizontal plane; if this rigidity stems from an elastic rheology that is confined to the uppermost lithosphere, we can conceive of a situation in which the upper lithosphere is strong enough to impose platelike behavior in a horizontal direction, but too weak to control vertical motions in underlying viscous regions. Lithospheric consumption can then occur primarily as a fluid process, with the brittle upper lithosphere responding passively to viscous consumption from below. We call this dynamical endmember "ablative subduction", and sketch it in cartoon form in Figure 1. Here, the viscous lower lithosphere flows downward as a fluid, with descent rates varying as a function of plate density. The more dense of two plates thus "subducts", while the less dense of the pair "ablates". Such a plate convergence will still leave a trench at the interplate boundary and a volcanic arc above the slab, but oceanic and continental subduction zones may differ in degree of ablation. If the ablating plate is extremely buoyant, as it would be if it were continental, then ablation rates will be low and subduction approximately one-sided. However, in a more symmetric, oceanic setting, ablation rates might be higher, so that the subducting slab will be composed of material originating on both sides of the trench.

This ablative model of plate consumption provides a simple, alternative means of interpreting subduction-related observations. We therefore explore its implications in more detail. In section 2 of this paper, we perform a series of simple numerical experiments simulating the behavior of an ablative subduction zone. We find that the ablative removal of even buoyant plate material may be a natural response to lithospheric convergence, and that buoyancy-controlled variations in ablation rate can strongly influence slab profiles. In section 3 , we consider how the model can be used to interpret observed patterns of interplate seismicity. Finally, in section 4 we examine how surface tectonic processes 
might reflect the response of the upper lithosphere to ongoing ablation at depth.

\section{NUMERICAL EXPERIMENTS}

We perform two sets of experiments, in which we model subduction as the foundering of a dense fluid lithosphere. In the first, we ask whether small amounts of crustal buoyancy, such as would be associated with oceanic island arcs, would necessarily prevent ablation's occurrence. In the second, we trace the development of simple ablative slabs and compare their profiles to those observed in nature.

These experiments explore the endmember case of purely ablative subduction, in which the elastic strength of the upper lithosphere (comprising crust and uppermost mantle) does not control vertical motions in the plates. Lithospheric consumption is then dominated by the fluid behavior of the viscous lower lithosphere (the part of the near-surface mantle that is more viscous than underlying material but is too warm to have an elastic rheology). Though this viscous layer might have different properties between continental and oceanic regions [Jordan, 1978], we assume for simplicity that its rheology is everywhere uniform. We further assume that this lower lithosphere is firmly attached to mantle and crustal layers overhead. Its ability to resist subduction is then largely determined by how much continental or island arc crust lies at the top of the plate (i.e., we assume that continental or island arc material imparts an overall buoyancy to the lithosphere as a whole).

\section{Plate Buoyancy and Rate of Ablation}

In our first set of experiments, two plates of varying density converge above a homogeneous mantle. (The experimental model, which uses a two-dimensional, Cartesian geometry under periodic boundary conditions, is described in detail in Appendix A.) In these experiments, the viscous lower lithosphere appears as a uniformly thick layer of Newtonian fluid, over which a platelike horizontal velocity boundary condition is applied to mimic the effect of the elastic upper lithosphere. A single trench divides the lithosphere into two plates; material within the left-hand plate is of higher density than material within the mantle, while the density of the right-hand plate varies between experimental runs. We initiate subduction by perturbing lithospheric fluid downward at the trench, after which we impose no further external guidance on the course of the experiment. The initially perturbed material flows downward, generating a mantle circulation that in turn drives the plates toward the trench. We assume that failure of the elastic lithosphere reflects removal of underlying material, in which case the requirement that plate consumption equals slab production defines the trench migration speed:

$$
\begin{aligned}
\mathbf{v}_{t} & =\mathbf{v}_{1}+\alpha\left(\mathbf{v}_{2}-\mathbf{v}_{1}\right) \\
\alpha & =\gamma_{1} /\left(\gamma_{1}+\gamma_{2}\right)
\end{aligned}
$$

where $\mathbf{v}_{t}$ is the trench velocity, $\mathbf{v}_{1}, \mathbf{v}_{2}$ are the vector velocities of the overriding and subducting plates, and $\gamma_{1}, \gamma_{2}$ denote the mass flux from each plate into the trench. (The ablation parameter $\alpha$ indicates the relative contribution made by the ablating plate to the slab and ranges from a value of zero in the one-sided model to 0.5 in the case of a symmetrical downwelling.) By measuring the flux of material entering the slab, we thus establish the trench motions appropriate for a purely ablative subduction zone.

Figure 4 shows the results of three runs. In the first, both plates are equally dense (Figure $4 \mathrm{a}$ ); in the others, the right-hand plate is either neutrally (Figure $4 b$ ) or moderately (Figure 4c) buoyant with respect to the underlying mantle. As expected, symmetrically dense plates sink as a symmetrical vertical downwelling (Figure 4a). We note, however, that a neutrally buoyant plate can also descend quite readily (Figure $\mathbf{4 b}$ ). Even though such a plate has no tendency to sink on its own accord, it is rapidly pulled down by shear coupling to the neighboring plate. Indeed, this coupling can drag even moderately buoyant material downward in a process of viscous ablation (Figure 4c). Thus plate buoyancy does not preclude plate descent; instead, increasing buoyancy serves merely to decrease the rate of ablation and thereby produce a displacement of the trench axis over time.

(a)

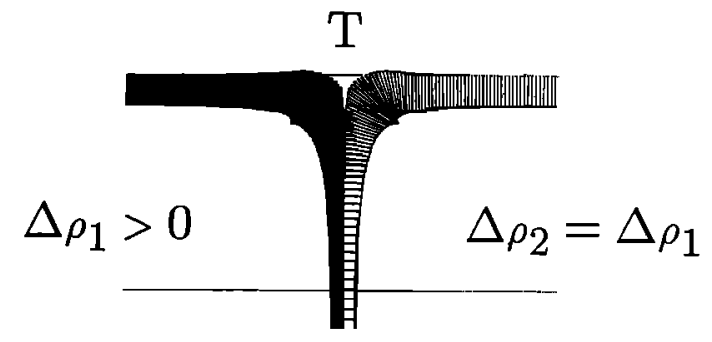

(b)

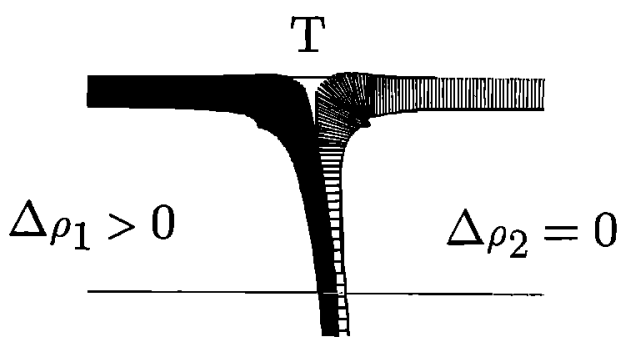

(c)

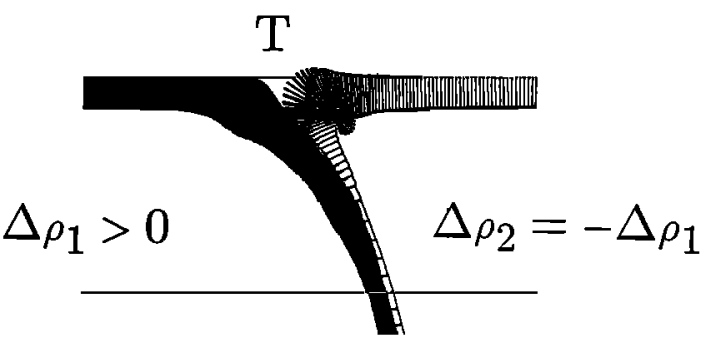

Fig. 4. Plate buoyancy and lithospheric consumption. Two plates converge at a trench, marked by $T$; ridges lie out of view. The left-hand plate (shaded) is of constant density; the density of the right-hand plate (open elements) varies between experiments. (a) Plates of equal density form a symmetrical downwelling. (b) A neutrally buoyant plate (open) can be readily entrained downward by a dense neighbor (solid). (c) This entrainment can remove even buoyant material (open) in a process of ablation. Plate buoyancy thus does not preclude ablation, but reduces the ablation rate and causes a lateral migration of the trench. Rectangles of constant area indicate the position of each density element (see Appendix A); $\Delta \rho$ indicates the difference in density between plate and mantle; a negative value of $\Delta \rho$ indicates that plate material is buoyant. 


\section{Ablation Rate and Slab Profile}

In the second set of experiments, we examine whether an ablative mode of subduction can produce realistic slab profiles. As we have assumed in our model that the lithosphere displays a predominantly fluid behavior, it might be argued that an ablative downwelling will not take on the slablike forms observed in nature. We therefore trace the development of fluid slabs and examine the forms they adopt under varying amounts of ablation. For simplicity, we begin each experiment with a uniformly dense lithosphere on either side of the trench and specify the ablation parameter $\alpha$ in each experimental run. We also impose a tenfold mantle viscosity jump at $670 \mathrm{~km}$, because in performing experiments with a variety of mantle viscosity profiles, we find that a viscosity increase with depth is required to satisfy seismic constraints on slab deformation. Our results suggest that not only can weak slabs take on realistic forms, but their profiles will also change with both the rate of ablation and the duration of subduction.

Physical basis. Governing the development of our fluid experimental slabs is the motion of the trench with respect to the mantle. In the framework of ablative subduction, marked differences in the buoyancy of continental and oceanic overriding plates lead to marked differences in ablation rate, in turn producing variations in the speed of trench motion (for a given convergence rate, increasing amounts of ablation will slow a trench until it effectively becomes a stationary, symmetrical downwelling.) As a migrating trench is essentially a moving conduit through which lithosphere enters the mantle, gross changes in its velocity will alter the path taken by sinking material and hence alter the shape of the slab. An ablative style of subduction should therefore lead to slab shapes and surface tectonics that systematically vary with the buoyancy of the overriding plate.

The idea of a link between trench migration and slab shape is not new. The basic concept, as proposed by Elsasser [1971] and Hyndman [1972], and outlined by Cross and Pilger [1982] and Garfunkel et al. [1986], is that a moving trench leaves behind a trail of subducting material much as a fast-flying paratroop transport leaves behind a trail of parachutes. By producing a horizontal spacing between successively subducted portions of the slab, trench motion leads to an inclined profile even though each slab element essentially free-falls through the fluid mantle. Thus a stationary trench should yield a vertical slab, and the role of migration is to reduce the dip.

Ablative subduction modifies the basic model by effectively slowing the migration rate for a given overriding plate velocity. If we assume that plates deform only at plate boundaries, then equations (1) and (2) give us the migration speed in any inertial reference frame (of which the hotspot reference frame is a convenient example). This seemingly minor adjustment to the migration model has several implications. Though slab dips are in some cases correlated with the absolute velocities of overriding plates [Cross and Pilger, 1982], a more global analysis shows the correlation to be relatively weak [Jarrard, 1986]. In the absence of ablation, this result implies that trench migration does not greatly affect slab shape. With ablation, the lack of a strong correlation is irrelevant, as migration may vary for a given plate speed. Ablation also suggests a way of easily controlling what we call the "effective migration" of a trench. What matters in any migration model is not the trench's velocity with respect to some absolute reference frame, but its velocity with respect to the mantle beneath it. If the underlying fluid contains a background flow, which we would expect in a convecting mantle overlain by moving plates, even a stationary trench will produce an inclined slab; similarly, a mantle that is flowing in the same direction as a migrating trench will reduce the effect of the migration. What should be noted is that in a one-sided subducting system with rigid plates, absolute trench motions and mantle flow fields are linked: if the only way to speed up a trench is to speed up the entire overriding plate, then we may well find that the local flow generated by plate-mantle coupling negates much of the effect of the velocity increase (Figure 5). Hence unless plates and mantle are completely decoupled, changes in the absolute migration of a one-sided trench need not produce corresponding changes in its effective migration. In an ablative system, however, variations in ablation rate can alter trench speeds without affecting plate motions; as plate-driven flow is unaffected, there is then a one-to-one correspondence between absolute and effective changes in trench motion. By directly controlling the effective migration of a trench, ablation may then exert a powerful control over the profile of descending slabs.

Results and Discussion. Results are shown for three experimental runs, in which $\alpha$ is set at 0 (Figure 6a), 0.15 (Figure 6b), and 0.333 (Figure 6c). Figure $6 a$ is thus the classical, one-sided endmember, while Figures $6 b$ and $6 c$ show the effects of low to moderate amounts of ablation in otherwise identical settings. Each slab is shown at the same stage in its development: in general, upper slab dips are initially steep and become shallower with time (Figure 7), eventually achieving the mature, quasi-steady state forms of Figures $6 a, 6 b$, and $6 c$. In every case, lithosphere and lower mantle viscosities are 10 times that of the upper mantle (higher lithospheric viscosities produce essentially the same slabs), and density anomalies are of constant magnitude through space and time. For graphical purposes, we have drawn the anomalies as linked rectangles of constant area; as the distance between anomalies changes through time, the width of each rectangle varies in inverse proportion and reflects the local strain. The plotted thickness of a slab thus indicates the amount of compression or extension it has undergone in its descent. Trenches are labeled " $T$ ", the overriding/ablating plates lie to the right of the trench, the subducting plates to the left, and the fluid associated with a given plate is distinguished by shading. For comparison, we show in Figures 8 and 9 the slab profiles inferred from seismic observations in a variety of subduction zones [Jarrard, 1986; Rasmussen and Humphreys, 1988; James and Snoke, 1990].

A comparison of the experimental results in Figures $6 a-$ $6 c$ with the real-world profiles in Figures 8 and 9 shows that variations in plate ablation can easily produce the entire observed range of slab dips. Deep, steep, Marianas-style slabs with curved upper sections develop when the overriding plate undergoes moderate amounts of ablation (Figure 6c). Lesser ablation rates cause the upper slab to straighten and take on extremely shallow dips, producing Chilean-style, shallow slabs extending several hundred kilometers inboard of the trench (Figure 6b). This reduction of dip with decreasing ablation acts most strongly on the uppermost portions of the slab. Because the deep slab is less affected, re- 

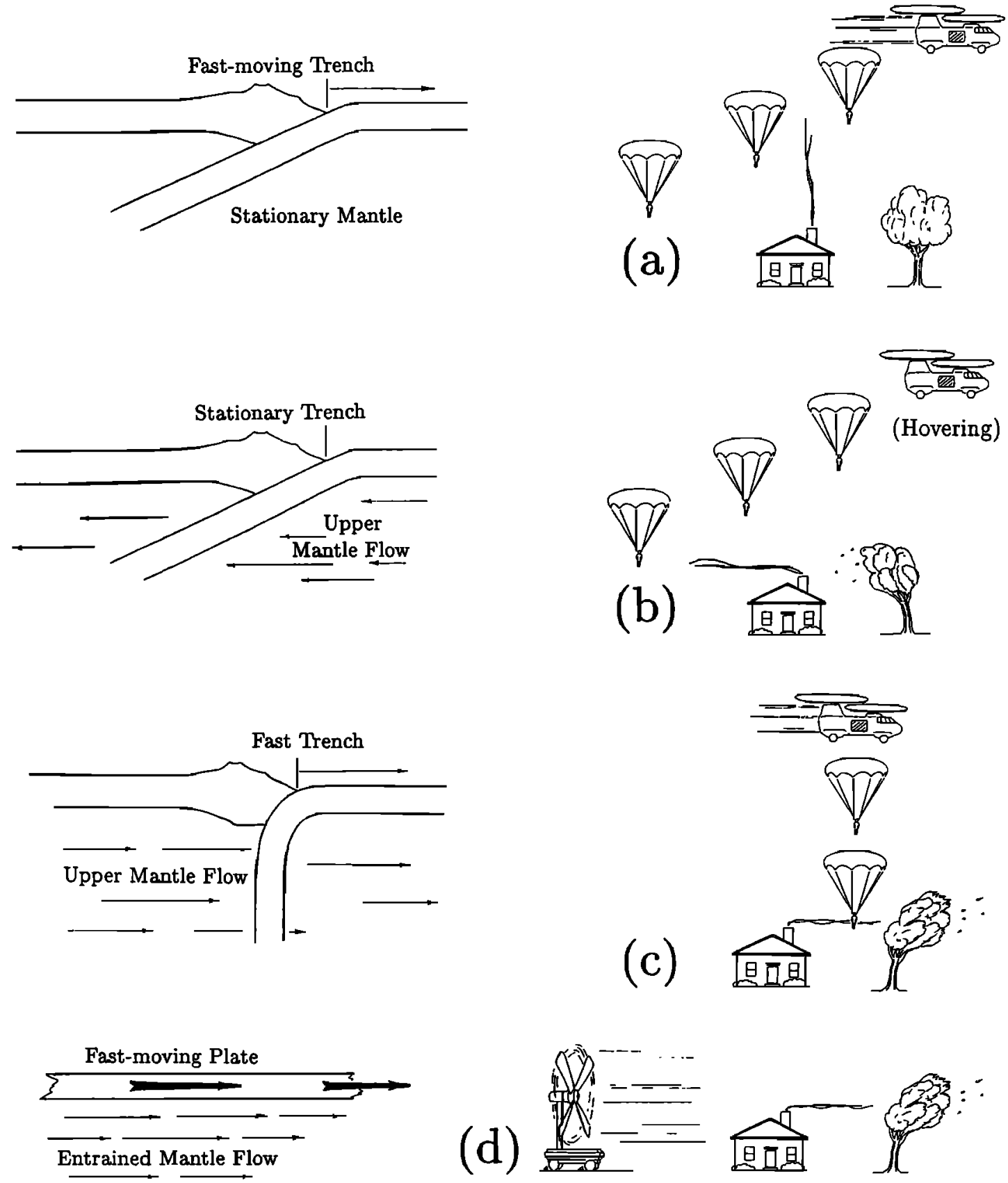

(c)

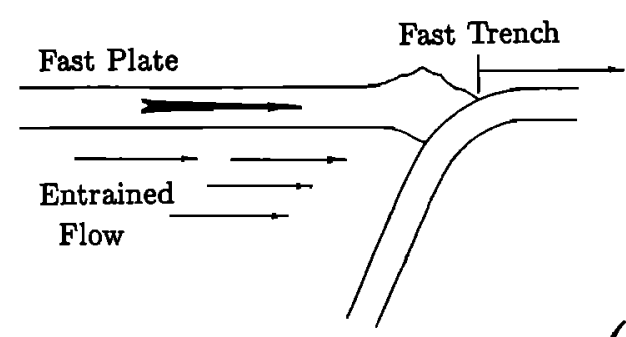

(e)

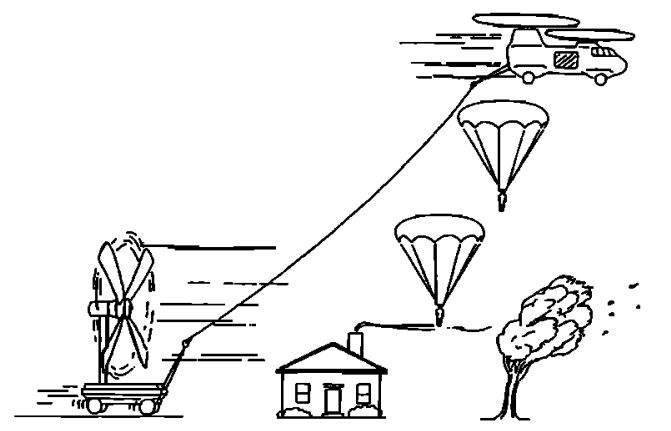

Fig. 5. Absolute versus effective trench migration. The shape produced by sinking slab elements depends upon the speed of the trench relative to the underlying fluid. Similar profiles may result from (a) a fast trench and quiescent mantle or $(b)$ a stationary trench and a fast flowing upper mantle; in both cases the effective migration rate is the same. (c) Conversely, a fast moving trench may have zero effective velocity. (d) Plate motions alter mantle flow fields unless completely decoupled. (e) In one-sided subduction, plate/mantle coupling will generate a flow associated with the trench's motion, thus limiting changes in effective migration. Even in the absence of the global mantle flow in Figure $5 b$, this coupling will result in steeper dips than produced in Figure 5a. 


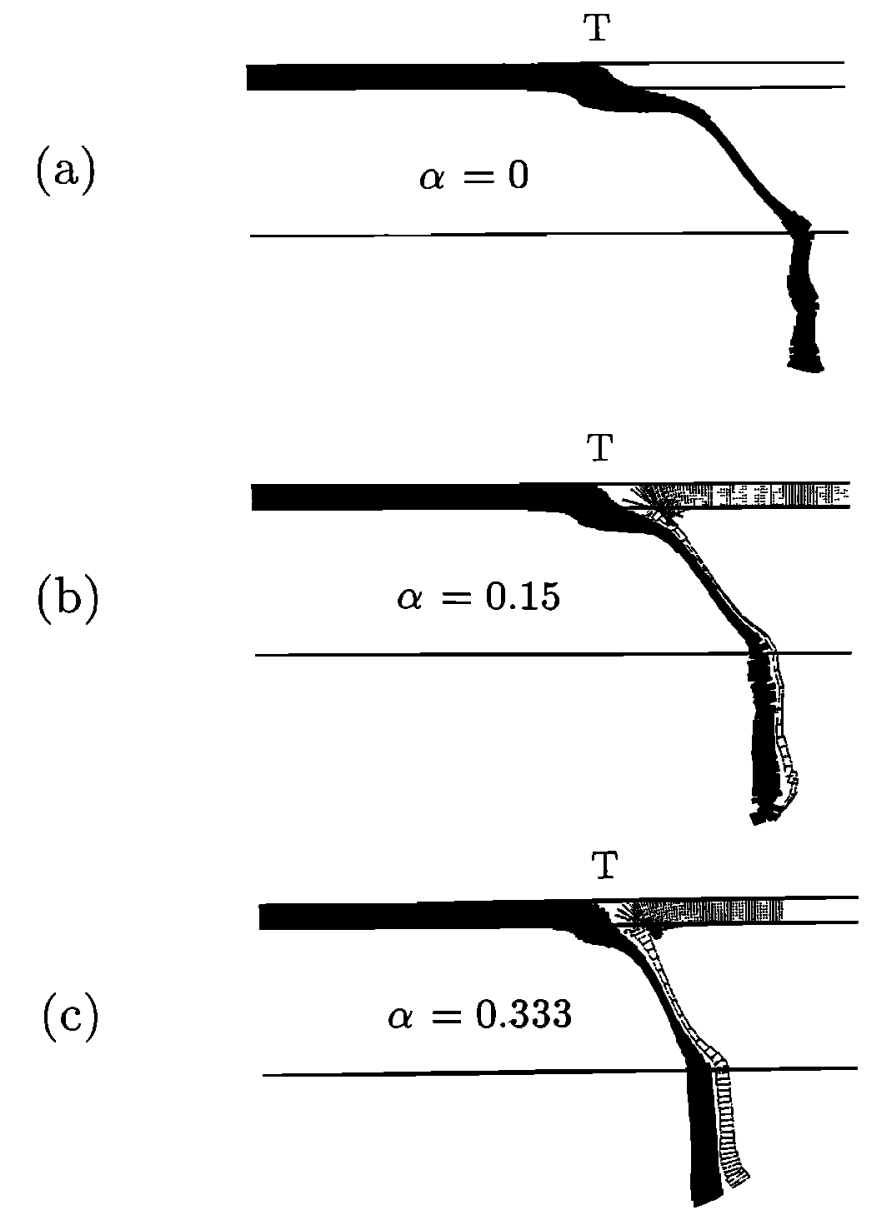

Fig. 6. Slab profiles generated with varying amounts of ablation; profiles are taken at the same stage of slab development, after initial transients have disappeared. Trenches are marked by $T$; ridges lie out of view. The subducting plate approaches from the left, the ablating or overriding plate from the right; solid slab elements are from the subducting plate, open elements are from the ablating plate. We have indicated the position of each density element with a constant area rectangle; the orientation of each rectangle shows the local dip, while the heights and widths indicate the strain accumulated by the slab over time. (a) $\alpha=0$ (one-sided subduction); (b) $\alpha=0.15$; (c) $\alpha=0.333$. Low ablation rates yield shallow-dipping, kinked slab profiles; increased ablation leads to a straightening and steepening of the profile.

duced ablation rates lead to kinked profiles in which shallowdipping upper slabs are joined to steep lower limbs. Curiously, strict one-sided subduction produces perhaps the least common slab shape, one in which the uppermost slab virtually underplates the continent for several hundred kilometers before abruptly turning downward (Figure 6a). Such a profile is consistent with proposed slab locations beneath Peru (Figure 9a) and the U.S. Pacific Northwest (Figure 9b) but does not resemble the straight slabs found in typical subduction cartoons [e.g., Cox and Hart, 1986]. More common slab profiles require the minor ablation rates of Figure $6 b$. It is noteworthy how little plate loss is required to change slab form: an ablation rate of a few percent turns the underplating slab of Figure $6 \mathrm{a}$ into the more conventional continental profile of Figure $6 b$, while a further increase to $33 \%$ yields the full-blown oceanic slab of Figure $6 c$.

We stress that the varied slabs in Figure 6 are produced without complicating variations in slab densities, slab strengths, plate driving forces, or externally imposed global
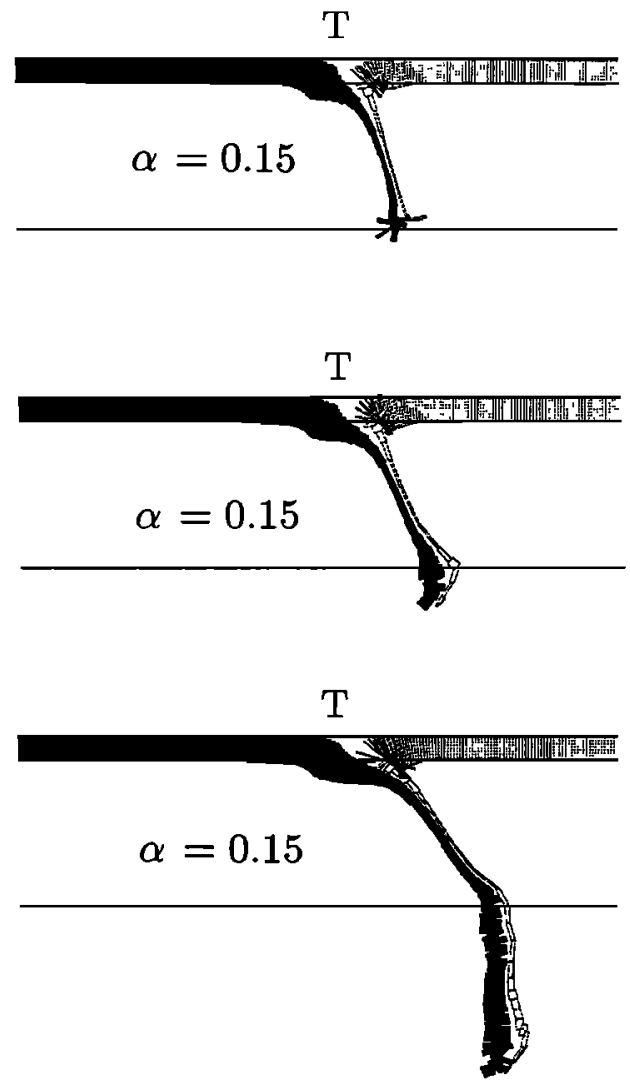

Fig. 7. Transient stages of development. $\alpha=0.15$, as in Figure $6 b$, showing the initial descent of a near-vertical, curved slab, and subsequent straightening, kinking, and shallowing of dip to a quasi-steady state form.

flow fields. All that has changed between experiments is the effective trench velocity, with the fastest migration occurring in the one-sided case of Figure $6 a$ and the slowest in the moderately ablative Figure $6 c$. Any mechanism that alters effective trench velocities will produce a similar effect; we have focused on ablation because it suggests a way in which continent-ocean and ocean-ocean convergence zones might behave differently. Potentially important mechanisms that we have not considered include global mantle flow and intraplate deformation behind a trench. Either may affect slab dips within a given region. However, global flow, whether driven by surface plates [Hager and $O^{\prime}$ Connell, 1978] or by more general convection within the mantle, does not obviously distinguish between different types of subduction zones. Plate deformation does make a distinction between oceanic and continental overriding plates, but in the wrong sense: in the absence of ablation, back arc deformation can move a trench relative to the bulk of the overriding plate, leading to effectively fast trenches where there is back arc spreading and effectively slow trenches where there is back arc compression. As oceanic overriding plates tend to be extensional whereas Andean-style continents undergo compression, plate deformation on its own should lead to shallow slabs in Marianas-style regions and steep slabs near continents. Such a result is the opposite of what actually occurs. While back arc deformation may help determine slab dips within a particular class of subduction (for example, the shallow Peru-Chile slab is steepest where back arc compression has been greatest [Wdowinski et al., 1989]), it cannot produce the gross differences observed between continental 

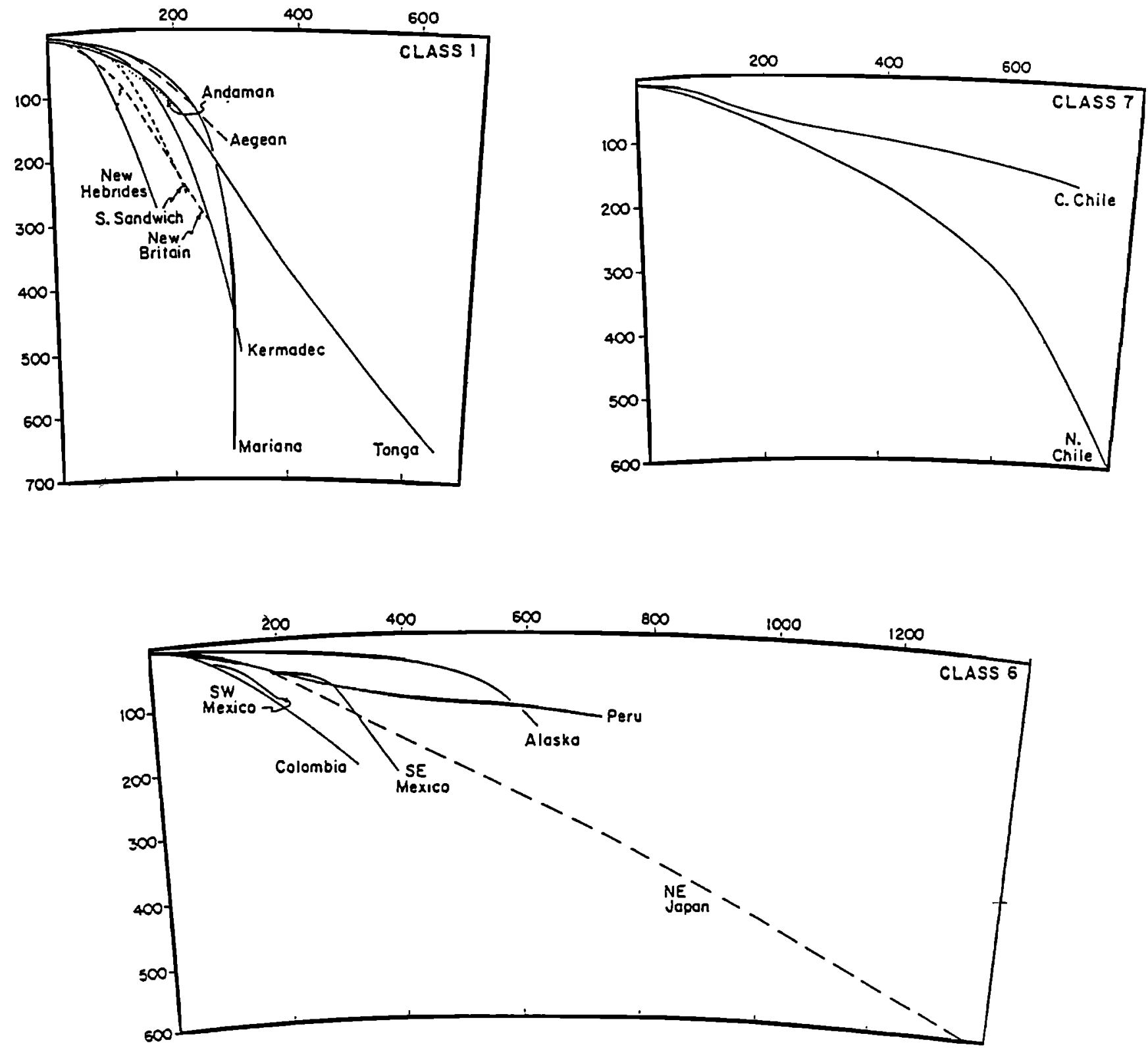

Fig. 8. Observed profiles of subducted slabs, taken from Jarrard, [1986]. Class 1 subduction zones are predominantly oceanic; classes 6 and 7 are continental in nature.

and oceanic subduction zones. It seems then that if changes in effective trench velocity are to produce such differences, these changes must come from ablation.

If ablative subduction does occur, our results suggest that it might be difficult to detect. We see in Figure 6 that material from ablating and subducting plates may adhere so closely as to be seismically indistinguishable below about $150 \mathrm{~km}$. Nearer the surface, ablation appears mainly as a general thickening of the overriding plate near the trench; the seismicity consistent with such deformation may become lost in the diffuse seismicity commonly observed at shallow depths [Isacks and Baraganzi, 1977] (Figure 10a). There is a suggestion of downwarping in the overriding plate below the Burmese Arc [Mukhopadhyay and Dasgupta, 1988] (Figure 10b), and perhaps increased resolution may someday settle the issue, but we suggest that ablation may be inherently difficult to discern through seismicity: if, as is generally assumed, slab seismicity is indicative of slab strength, then the stronger of two converging and subducting plates should be the more seismically active. Observed slabs are almost always associated with cold lithosphere, while overriding plates are composed of weaker continental, island arc, or back arc material. If ablation were to occur, the failure of the weak overriding plate may then be relatively silent, in which case we would observe the deformation of only the more rigid subducting plate. If that were the case in Figures $6 b$ and $6 c$, only material from the left-hand plates (solid area) would be visible. As an extreme but illustrative example, we show in Figure 11a a symmetrical downwelling $(\alpha=0.5)$, in Figure $11 b$ the same downwelling with one plate/slab invisible, and in Figure 11c the observed profile of the Marianas slab [Creager and Jordan, 1986].

That the downwellings in Figure 6 can resemble observed slabs is in some ways surprising: whereas subducting lithosphere is generally assumed to be strong (hence the term "slab"), these downwellings have no strength at all. Their 


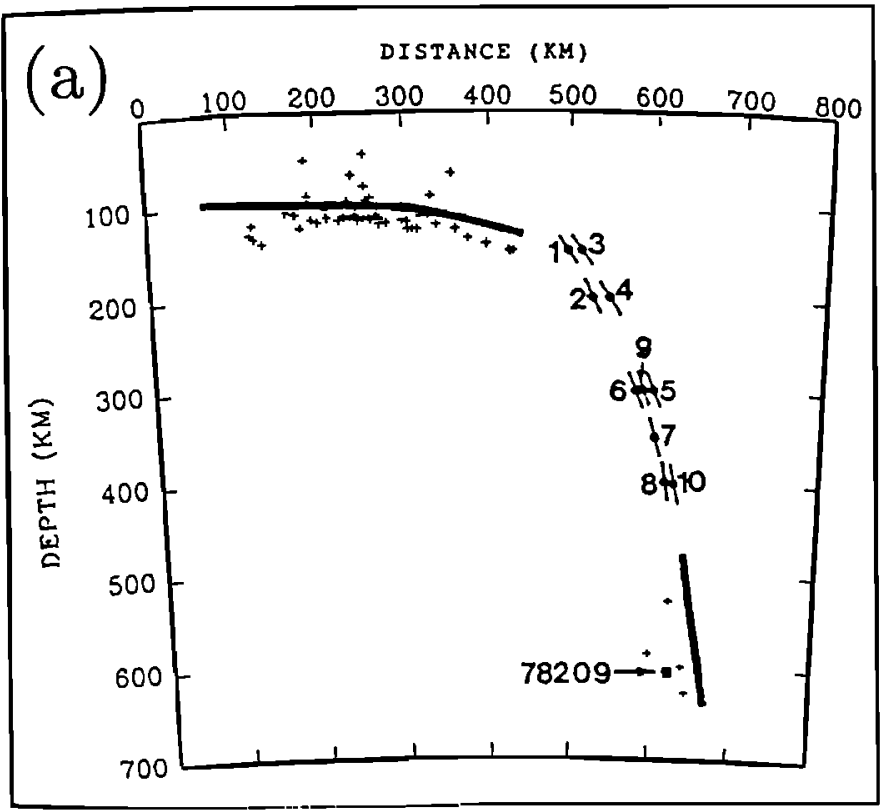

(b)

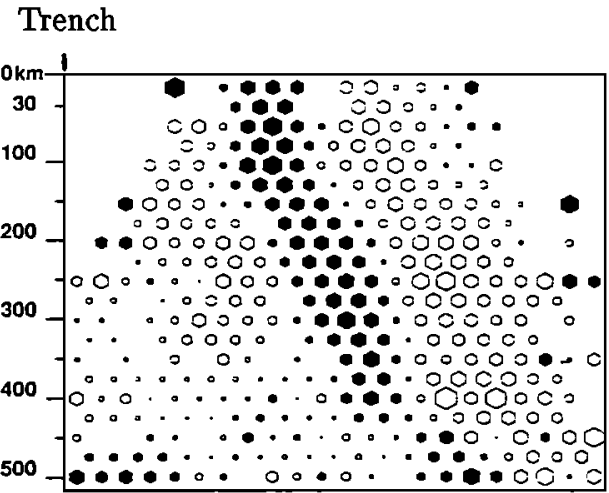

(c)

$\alpha=0$

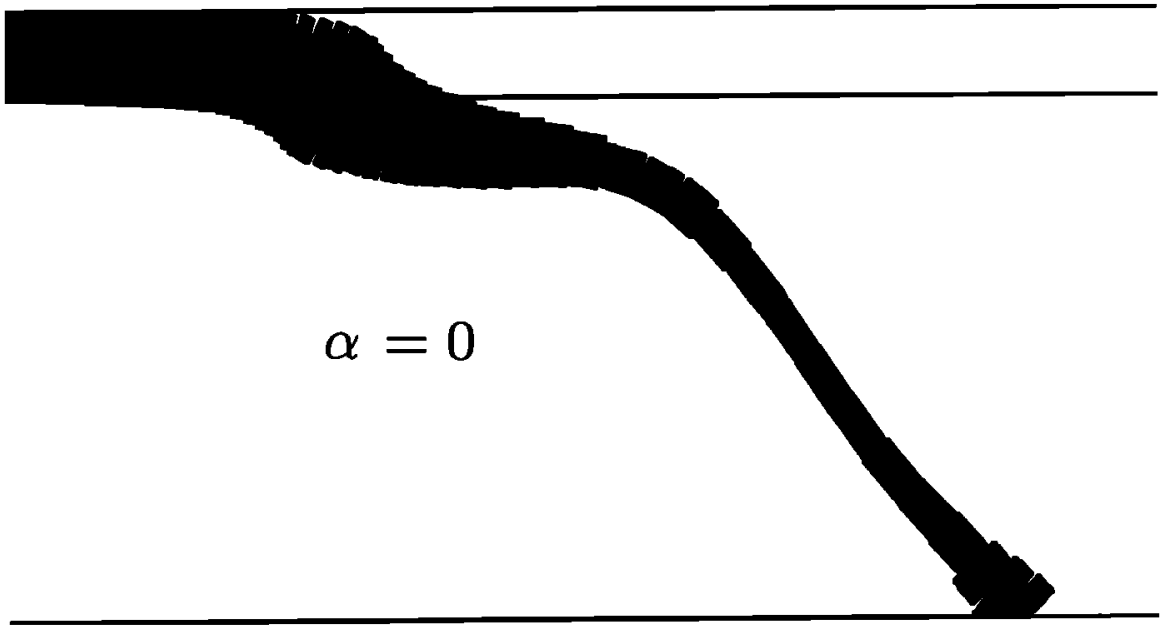

Fig. 9. Extreme continental-style slabs: (a) Peru [from James and Snoke, 1990], and (b) Washington and Oregon [after Rasmussen and Humphreys, 1988]. (c) The one-sided subduction $(\alpha=0)$ result of Figure $6 a$ is repeated for comparison.

slablike forms arise not from a slablike resistance to deformation, but from the sculpting action of local mantle flow fields. In addition to generating plausible profiles, these flow fields also produce downdip slab deformations that are consistent with frequently observed seismic focal mechanisms [Isacks and Molnar, 1971]: as indicated by the patterns of thickening and thinning in Figure 6, the downwellings undergo compression at the trench, extension at intermediate depths, and further compression as material approaches the high-viscosity lower mantle. Collectively, our results suggest that flow-induced deformation can account for much of a slab's shape. They also suggest that inferring a slab's theology and behavior from its seismic profile is not a straightforward task; for example, if we were ignorant of the downwellings' true nature, we might examine the kinked profile of Figure $6 a$ and erroneously interpret it as a shallow, rigid slab which has been broken and bent downward midway through its descent.

Finally, while we have focused here on mature slab profiles, the time development shown in Figure 7 is of potential significance. Oceanic subduction zones are thought to be generally younger than those involving continents: the Marianas zone, for example, is estimated to be $45 \mathrm{~m}$.y. old, while the shallow slab beneath the Andes has been subducting for over $200 \mathrm{~m} . y$. [Jarrard, 1986]. This relative youth might account for some of the steepness characterizing oceanic slabs. Our experiments suggest that dips become shallower with time, rapidly at first, then more slowly, and it may be that young steep slabs are displaying transient behavior. Such a shallowing would explain why arc-trench distances seem to grow with subduction duration [Dickinson, 1973]: as subduction progresses, the source region for arc magmatism 

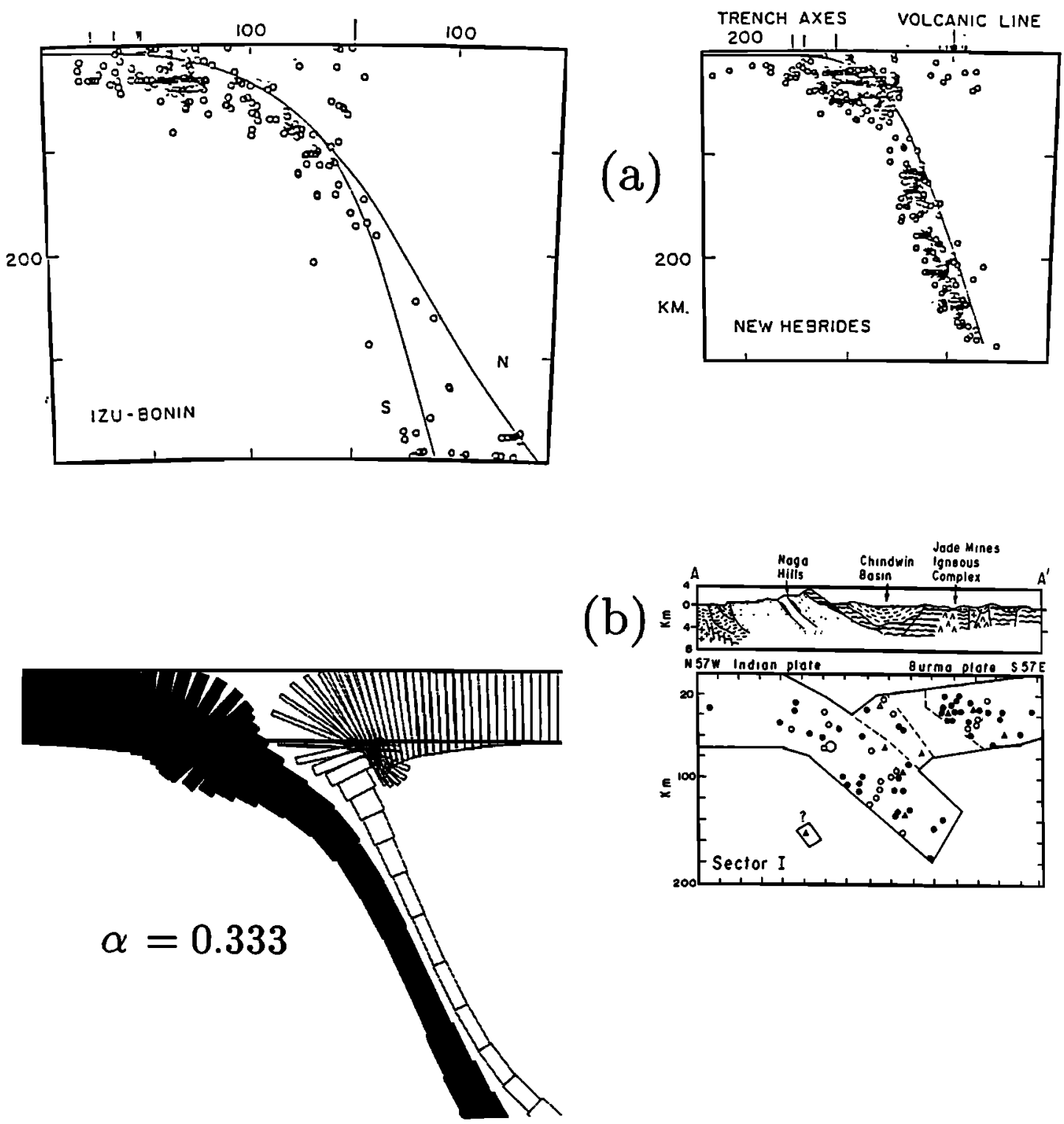

Fig. 10. Observability of plate ablation I: (a) Earthquake centers and original proposed slab profiles [from Isacks and Baraganzi, 1977]. (b) Proposed downwarping of Burma plate below Burmese Arc [after Mukhopadhyay and Dasgupta, 1988]. A close-up of the moderately ablative $(\alpha=0.333)$ slab of Figure $6 c$ is shown for comparison.
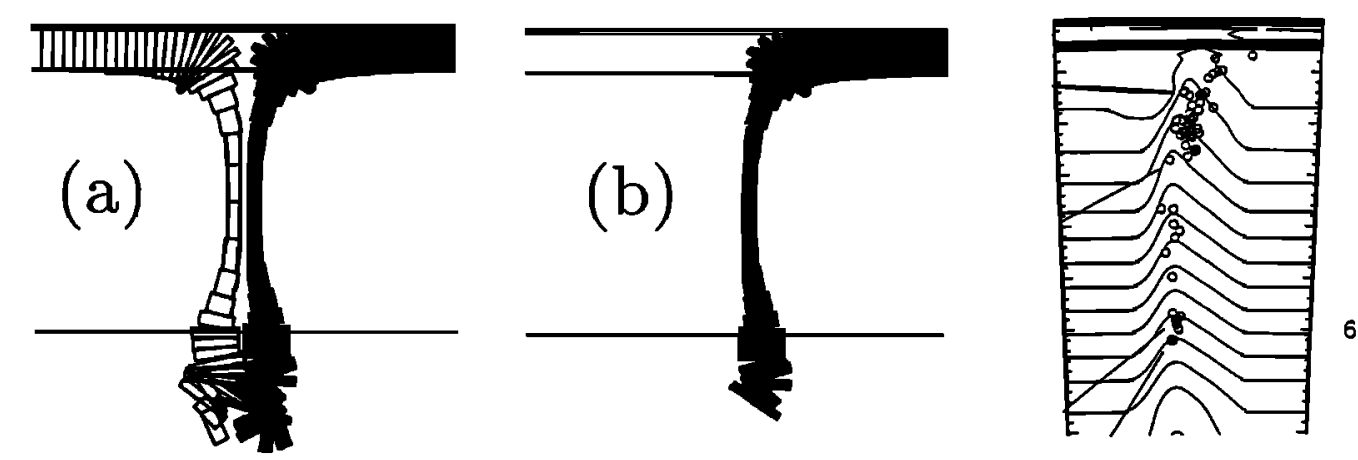

Fig. 11. Observability of plate ablation II: (a) Profile of symmetrical downwelling $(\alpha=0.5)$. (b) Observed profile if material from one plate subducts aseismically. (c) Proposed profile of the Marianas slab [from Jarrard, 1986]. 
might swing away from the trench as the dip of the slab decreases. It is also conceivable that ablation may slow a slab's evolution toward a shallow mature profile; in such a case, a lesser degree of ablation than implied by our experiments might still yield steep dips in a region that is relatively young.

\section{Response of UPPER Lithosphere to Ablation, INTERPLATE SEISMICITY, AND SEISMIC Moment Release Rates}

We next consider how a two-sided mode of plate descent may affect the seismicity of convergent plate boundaries. Earthquakes along these boundaries typically possess focal mechanisms that are aligned with the upper slab; they are therefore interpreted within the classical model as showing slip between subducting and overriding plates. Within the ablative model, we would interpret these earthquakes rather differently: rather than mark the simple passage of one plate beneath another, they may indicate how the elastic lithosphere responds to the consumption of underlying material.

If the viscous lithosphere descends in the manner of our experiments (e.g., Figure 4c), the upper lithospheric response might take on a number of different forms. We would expect a simple behavior to be shown by the "subducting" plate (i.e., the more rapidly descending of two plates): because the angle between plate and slab is relatively open, the elastic lithosphere may simply bend downward to follow the axis of the downwelling slab. However, a more complex response might be shown by the more slowly descending, "ablating" plate: here, the angle between plate and slab is considerably more acute, and further complications can arise from the presence of buoyant continental or island arc crust. If the upper part of this plate is easily bent and possesses little buoyancy, it might still simply bend downward (Figure 12a). Alternatively, however, it may crumple via crustal shortening (Figure 12b) or be worn away in a process classically referred to as tectonic erosion [Bloomer, 1983] (Figure 12c). Thus the upper lithosphere, whose deformations should be responsible for the bulk of interplate seismicity, might respond to ablation in a variety of ways.

This aspect of the ablative model may help explain why rates of interplate seismicity vary widely from one subduction zone to another. The variations can be seen in Table 1 , where we have tabulated the ratio of seismic slip rate to tectonic slip rate for a number of major subduction zones [after Peterson and Seno, 1984]. Seismic slip is the degree of interplate thrusting as inferred from rates of seismic moment release; tectonic slip is that inferred from relative plate velocities under the assumption of classical subduction. The ratio between the two is given by $\beta ; \beta=1$ thus implies that plate convergence is entirely taken up by seismic slip along thrust planes, while a paucity of seismic release will yield a value of $\beta$ closer to zero. Early studies of seismic and tectonic slip rates had found a reasonable correlation between plate convergence velocity and seismic moment release [Davies and Brune, 1971; Sykes and Quittmeyer, 1981], but the more recent results presented in Table 1 [Peterson and Seno, 1984] show a surprising degree of variability. In general, the relative seismicity of oceanic subduction zones is far less than that of continental regions; indeed, moment release rates in the classic Marianas-style zones (Marianas, Izu-Bonin, Tonga, and New Hebrides) are an order of magnitude lower than rates in continental locales. However, a no- (a)
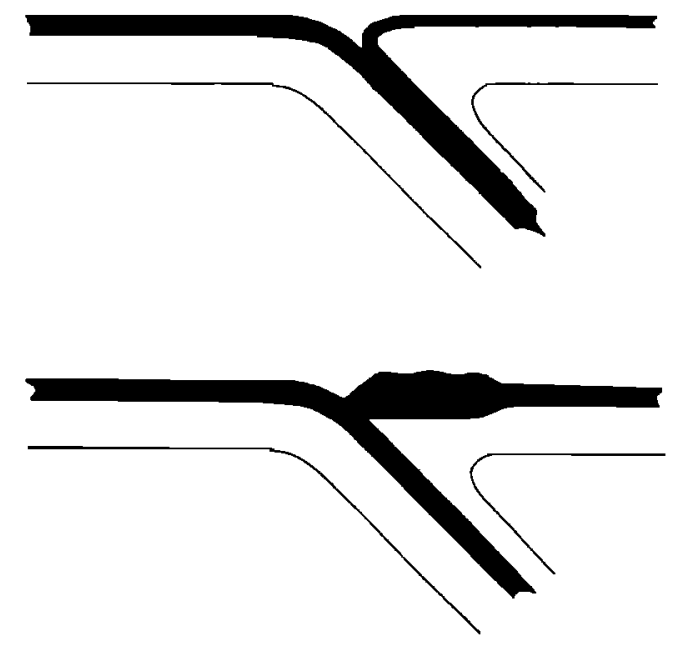

(c)

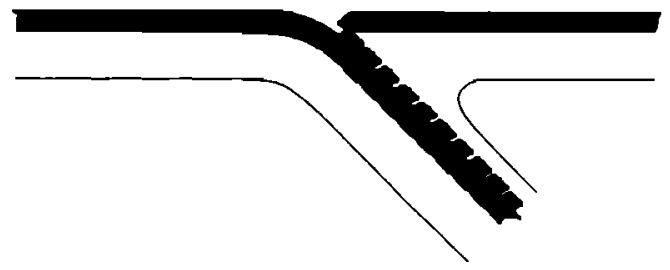

Fig. 12. Upper lithospheric response to ablation of the lower lithosphere. As the viscous lithosphere (open) flows away as a fluid, the elastic lithosphere (solid) must deform in response. In the ablating plate, this response may take the form of (a) a downward bending, (b) crustal shortening, or (c) tectonic erosion.

table exception to this trend is given by the Aleutian trench: not only is its effective seismicity much greater than that of the other oceanic regions, but its value of $\beta$ is high even with respect to continental zones.

Within the classical subduction model, earthquakes at the top of the Benioff zone show either interplate slip (Figure 13a) or vigorous tectonic erosion (Figure $13 b$ ); in both cases, the rate of seismic moment release should ideally vary with the rate of plate convergence, yielding consistent values of $\beta$. To explain the variations seen in Table 1 , we would therefore invoke a selective decoupling between plates in regions of extensional tectonics and/or where unusually dense lithosphere is subducted [Uyeda and Kanamori, 1979; Peterson and Seno, 1984]. Thus amended, the classical model can reasonably explain much of the observed pattern. However, we can also use the ablative model to devise a more fundamental explanation. If ablative subduction occurs, then the different moment release rates in Andean-style and Marianasstyle regions may reflect differences in ablation rate and upper lithospheric response; in addition, we may further interpret the active seismicity of the Aleutian trench as reflecting a relatively rare occurrence of true classical subduction.

We consider the Aleutian case first. The occurrence of classical subduction in this region is suggested by the unusual geometry of the converging plates. Here, where lithosphere of Mesozoic age overthrusts younger, early Cenozoic material [Addicott and Richards, 1981], the overriding plate is not only unusually old, but it is apparently stronger and more massive than the plate that is being subducted. This geometry is unique among major subduction zones (though it may be found in less well-developed areas such as the eastern edge of the Caroline Plate [Hegarty et al., 1980]). 
TABLE 1. Ratio of Seismic Slip to Plate Tectonic Slip in Continental and Oceanic Subduction Zones

\begin{tabular}{|c|c|c|}
\hline Trench & Length, km & $\bar{\beta}$ \\
\hline \multicolumn{3}{|c|}{ Continental Zones } \\
\hline Alaska & 1350 & 0.77 \\
\hline Kamchatka & 1280 & 0.67 \\
\hline Nankai & 750 & 0.50 \\
\hline Mexico & 1150 & 0.38 \\
\hline Peru-Chile* & 5300 & 0.37 \\
\hline Kurile & 1210 & 0.36 \\
\hline Columbia & 650 & 0.33 \\
\hline Japan & 650 & 0.24 \\
\hline Cen. America & 1580 & 0.10 \\
\hline Sumatra & 1930 & 0.05 \\
\hline Weighted mean & & 0.36 \\
\hline \multicolumn{3}{|c|}{ Oceanic Zones } \\
\hline New Hebrides & 1800 & 0.16 \\
\hline Kermadec & 700 & 0.13 \\
\hline Tonga & 1450 & 0.08 \\
\hline Ryukyus & 1300 & 0.05 \\
\hline Marianas & 2150 & 0.01 \\
\hline Izu Bonin & 1240 & 0.01 \\
\hline Java & 1800 & 0.00 \\
\hline Weighted mean & & 0.06 \\
\hline Eastern Aleutians & 1200 & 0.84 \\
\hline Western Aleutians & 740 & 0.31 \\
\hline
\end{tabular}

After Peterson and Seno, 1984. $\beta$ is the ratio between observed seismic slip and the amount of slip expected from relative plate motions. "Weighted mean" is the average value of $\beta$ over several trenches, weighted by trench length. Trenches are classed as continental or oceanic according to tectonic style (Ryukyus) or because of crustal type [Jarrard, 1986] of the overriding plate (all others). In general, continental-style subduction zones have effectively higher rates of seismicity than oceanic-style zones, a pattern consistent with the ablation and rolling under of oceanic forearcs. Note that the Aleutian zone is a significant exception to the rule (see text).

* $\beta$ for Peru-Chile is the average $\beta$ (weighted mean) over 5 trench segments.

The overriding plates in most other subduction zones are most likely weaker, but more buoyant, than their subducting neighbors, particularly when continents or young back arc basins are found behind the trench. In such regions, plate buoyancy seems to determine the identity of the overriding plate, a dependence essential to the ablative model. In contrast, the polarity of Aleutian subduction seems to arise not from the overriding plate's buoyancy, but from its mechanical resistance to bending. Subduction in this region might then be best interpreted as a classical overlapping of rigid plates. We should expect such a convergence to be seismically active.

Elsewhere however, in the majority of subduction zones, the ablative model may apply. In such regions, rates of seismic moment release may vary with both the rate of ablation and the behavior of the upper lithosphere. In a region of low ablation (as when a continent borders the trench), slip between buoyant and dense masses should yield high rates of seismic moment release. But when ablation is significant, there is little interplate slip within the viscous lower lithosphere (Figures $13 c-13 e$ ). This absence of slip is consistent with the seismicity drop that generally occurs below a depth of $60 \mathrm{~km}$ [Peterson and Seno, 1984]. Activity in the seismo- genic zone will then depend upon how the uppermost plate responds to the removal of underlying material. If the upper plate undergoes crustal shortening, then there is still a sense of interplate slip, and earthquakes again should be present (Figure 13c). If ablation is accompanied by a tectonic erosion of the elastic lithosphere, thrusting will also still occur (Figure 13d). However, if the upper layer of the ablating plate simply tucks downward at its leading edge, then the relative slip between plates is substantially reduced (Figure $13 e$ ) and subduction will be comparatively aseismic.

We would therefore expect the seismicity of ablative subduction zones to show a characteristic pattern. High rates of seismic moment release should be found in Andean-style zones: here, ablation rates will be reduced by continental buoyancy, and observations of crustal shortening [Isacks, 1988] and tectonic erosion [Stern, 1989] may account for any ablative losses that do occur. In contrast, the seismicity of Marianas-style zones might be comparatively weak: higher plate densities should foster higher rates of ablation, there is no observed crustal shortening, and the young (and thus weak) overriding plates typically present should more likely bend downward than erode at the surface. Hence the observed aseismicity of Marianas-style subduction and the activity of Andean regions may reflect varying degrees of buoyancy-controlled ablation.

Thus we can simply interpret the seismic observations in Table 1 if both classical and ablative modes of subduction occur in different parts of the world. Such an interpretation is certainly not unique: as noted earlier, if we correlate aseismic convergence with a decoupling between converging plates, we can reasonably account for the seismic data using the classical model alone. The appeal of the ablative model in this regard is that it permits us to assume a consistent degree of plate coupling worldwide. Consistent coupling may then be used to simply explain several other differences that exist between oceanic and continental subduction zones. For example, strong interplate coupling would explain why Marianas-style slabs, besides dipping more steeply than those beneath continents, also seem to descend to much greater depths. The steepness and deepness of these slabs implies a rapidity of descent that is lacking in continental areas. If plates are decoupled, then it is not clear how the character of the overriding plate can affect slab speeds. But if plates are coupled, then we would expect slabs dragging along pieces of buoyant continental lithosphere to descend more slowly than those joined to denser oceanic material. Strong interplate coupling can also explain why we associate compression with continents but extension with oceans: a shallow-dipping, one-sided slab that is shear-coupled to an overriding continent should produce back arc compression, while a steeply dipping ablative slab, by drawing material together from both sides of the trench, should instead induce tension. In these respects, ablative subduction not only explains seismic observations, but it provides a simple way of relating slab descent to the tectonics of the overriding plate.

\section{Tectonic Implications}

We have seen thus far that an ablative subduction model is dynamically plausible, that it is consistent with seismic observations, and that it can be used to explain why Andean- and Marianas-style slabs are fundamentally different in profile. We now examine how the model may be used in the interpretation of surface tectonics. 


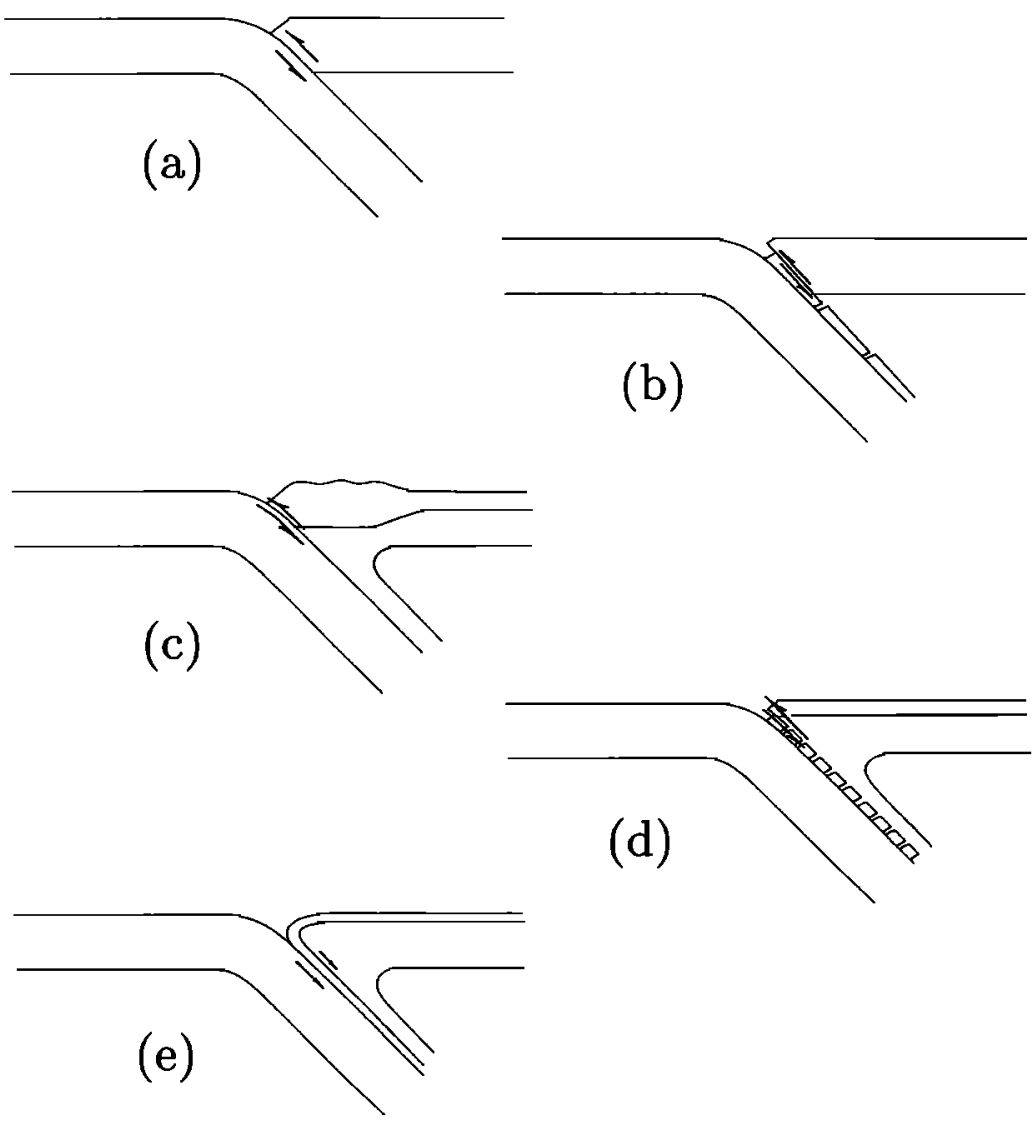

Fig. 13. Ablation and interplate seismicity. (a) and (b) In classical subduction, thrust-faulting earthquakes show either the slip between overlapping plates, or the erosion of the overriding plate. (c), (d), and (e) In ablative subduction, though there is no localized shear or slip zone in the fluid lower lithosphere, earthquakes can occur in the elastic upper lithosphere if crustal shortening (Figure 13c) or tectonic erosion (Figure 13d) occur. However, if ablation is vigorous and the ablating plate turns downward (Figure 13e), interplate slip may be considerably reduced, and subduction may then be relatively aseismic.

\section{Ablation in Andean Subduction Zones}

The low-ablation endmember of the ablative model is Andean-style subduction, in which a large continent comprises the overriding plate. Here, the ablative model can be most simply applied, for as continents are not platelike in their behavior (and in some cases may be modelled as thin viscous sheets [England and McKenzie, 1982]), their rheology is well suited to ablative consumption. What can preserve continents, and create the impression of classical subduction, is a combination of crustal thickness and buoyancy. The presence of a thick, buoyant continent imparts a significant degree of buoyancy to the overriding plate as a whole. If plate buoyancy governs the flux of material into the slab (Figure 4), ablation rates can be severely curtailed so long as crust and lower lithosphere are firmly joined.

Given the apparent fluidity of continental crust, the surface appearance of Andean-style ablation can be relatively simple. Since continental crust is buoyant, it should not descend unless dragged downward by sinking material; since it is weak, the descent of a given crustal element will not directly affect more distant regions. Thus continental crust should not descend until it is virtually in contact with the subducting plate. As crustal ablation is then localized within the immediate vicinity of the trench, the consumption of a fluid continent can take on the appearance of classical tectonic erosion. Ablation can thus account for observa- tions of tectonic erosion in the Andean zone, which appears to take place at a rate of $1 \%-5 \%$ [Stern, 1989].

Conversely, the surface response to Andean-style ablation might at times be more complex. So long as continental crust is well attached to material below, ablation can be governed by tectonic erosion, and subduction may then take on a classical outward appearance. But if the lower lithosphere is not firmly attached to overlying crust, then it may conceivably delaminate from the buoyant part of the plate. In such an event, the ablative removal of the viscous lithosphere can suddenly increase in vigor. As this ablation need not be localized about the trench, it might then yield a thickening and lateral shortening of the continental crust (Figure 14). Such a process would explain certain anomalies of slab profile that are found in the Andean subduction zone. Here, the Peru-Chile slab varies in profile along strike, and displays a marked steepening where it passes beneath a zone of pronounced crustal shortening (Figure 15 [Isacks, 1988]). Within the ablative model, we might interpret the crustal shortening as a surface response to a pulse of ablation in the lower lithosphere. This temporary transition to vigorous ablation might then be reflected in the observed local steepening of the slab.

\section{Ablation in Marianas-Style Subduction Zones}

Intermediate, time-varying ablation would be expected to occur in Marianas-style subduction zones. Such regions are 
Tao and O'Connell: An Ablative Model of Subduction

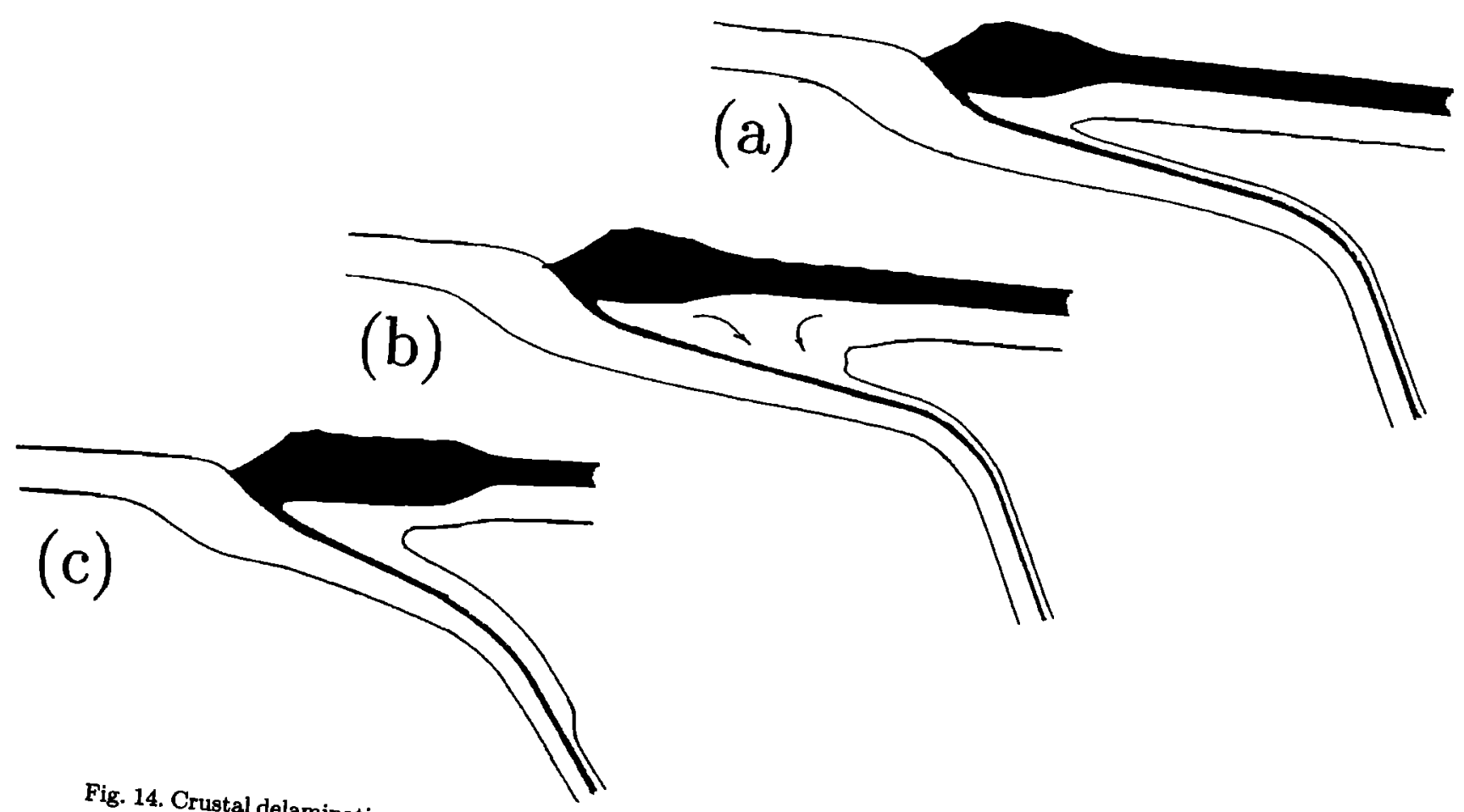

crust (solid) should lination and lateral shortening.

subcrustal lithosphere (open), a lan, and subduction is f normal Andean subduction, the buoyancy of

pulse of ablation may then ), a large part of the lower lithospe-sided. (b) If a fluid ingyancy of continental

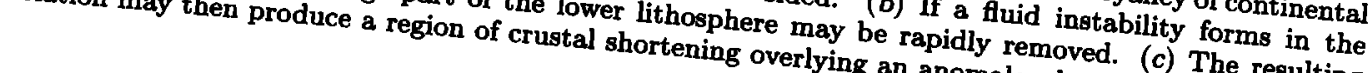
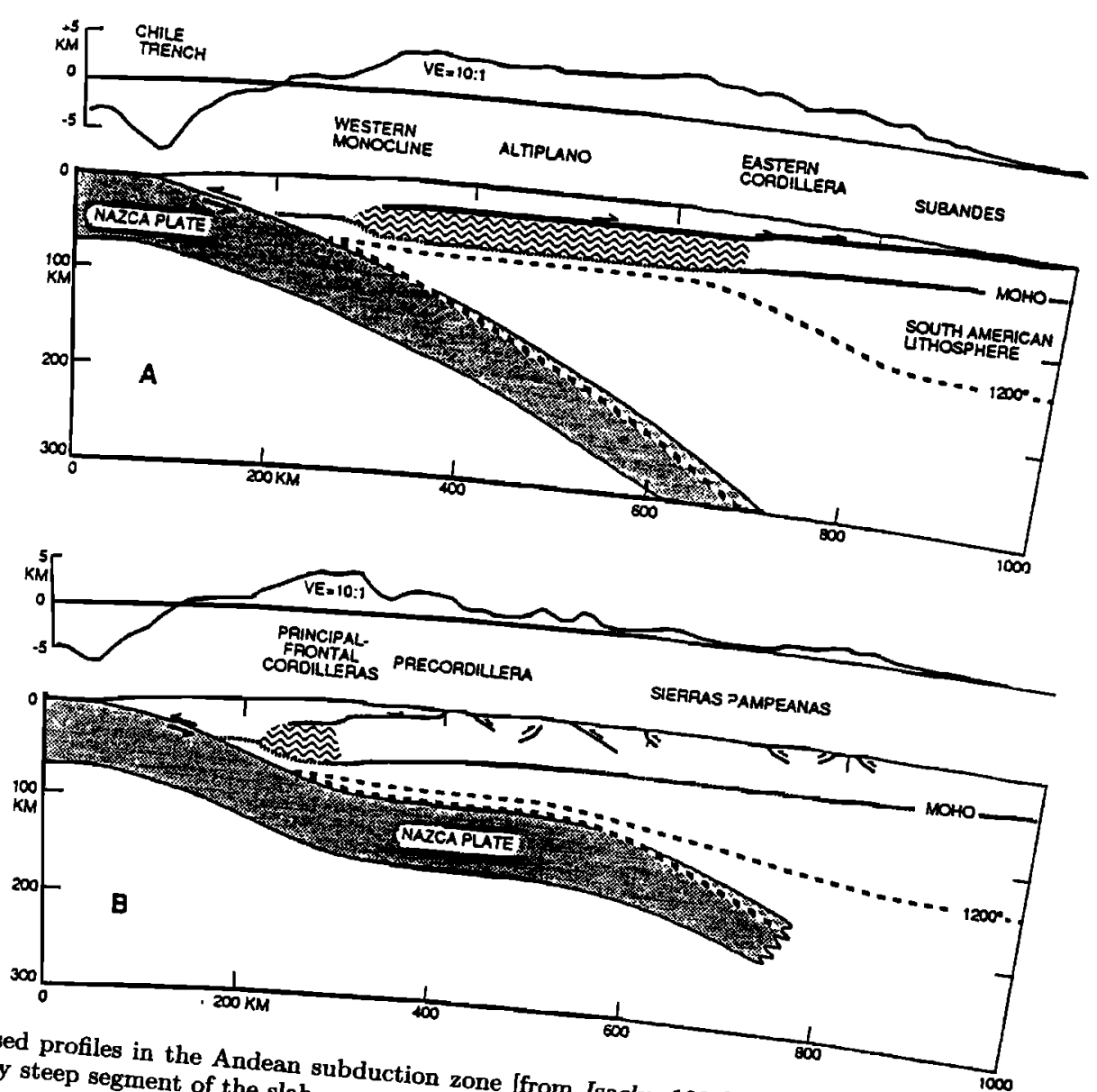

Fig. 15. Proposed profiles in the Andean subduction zone [from Isacks, 1988].
overlies a locally steep segment of the slab. 


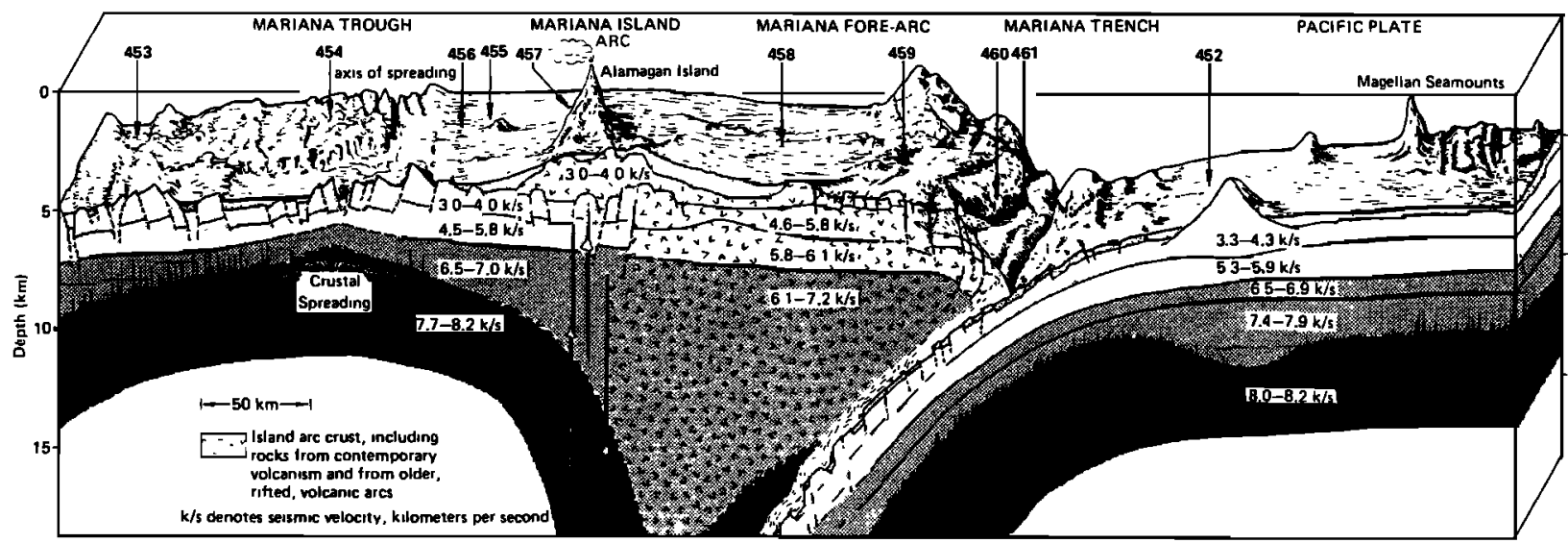

Fig. 16. Physiographic diagram and crustal structure across part of the Marianas subduction zone [from Hussong et al., 1981]. The active arc overlies part of the back arc basin, the forearc is composed of island arc material, evidence of subsidence is found in the trench wall, and deep refractors within the overriding plate dip towards the trench.

characterized by periods of back arc quiescence interspersed with pulses of back arc spreading, the latter often beginning with a rifting of the island arc [Karig, 1972; Taylor and Karner, 1983]. These extensional pulses, by splitting the arc in two, might limit the accumulation of large buoyant masses and prevent the development of Andean-style asymmetry. However, the periodic creation of fresh back arc material will also ensure that plate densities do not become overly symmetric: in these regions, the mature Pacific plate typically lies to one side of the trench, with much younger and warmer back arc basins on the other. Extensional subduction zones thus occupy a middle ground between the extreme plate asymmetry of an Andean-style region and a symmetric convergence of mature oceanic plates.

The intermediate nature of Marianas-style subduction should lead to the formation of a subduction zone that is clearly asymmetric but which features a more steeply inclined slab than is found in Andean regions. Given that weak, young back arc basin material makes up much of the overriding plate, we would expect ablation to be accompanied by a rolling under of the overriding plate edge. This rolling motion would be consistent with the previously discussed seismic moment release pattern, and would also account for observations of near-vertical normal faults in the Marianas forearc [Mrozowski and Hayes, 1980], as well as for an apparent trenchward dipping of deep seismic refractors within the Marianas forearc [Latraille and Hussong, 1980] (visible in Figure 16 [from Hussong et al., 1981]), and for seismic and tectonic evidence of surficial tension between the Marianas trench and back arc basin [Hussong and Sinton, 1980; Hussong and Fryer, 1981] (such a tension might arise from bending of the forearc or from coupling between descending forearc and slab).

Left alone, the rate of ablation in a Marianas-style subduction zone should tend to decrease over time. The reasons are summarized in Figure 17. Because the distance between arc and trench should remain more or less constant (barring changes in slab dip), an observer on the overriding plate will see the active arc move in a back arc direction as forearc consumption continues. Because of this motion, a given arc volcano will eventually become inactive, to be replaced by new volcanoes in the former back arc region. Over time, inactive arc fragments will then approach the trench, perhaps wearing away under surface weathering processes and (a)

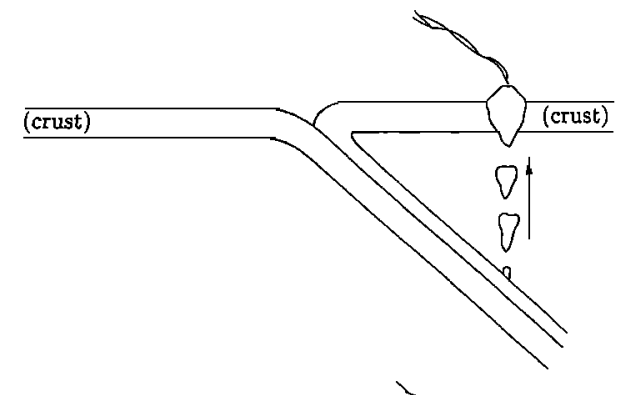

(b)

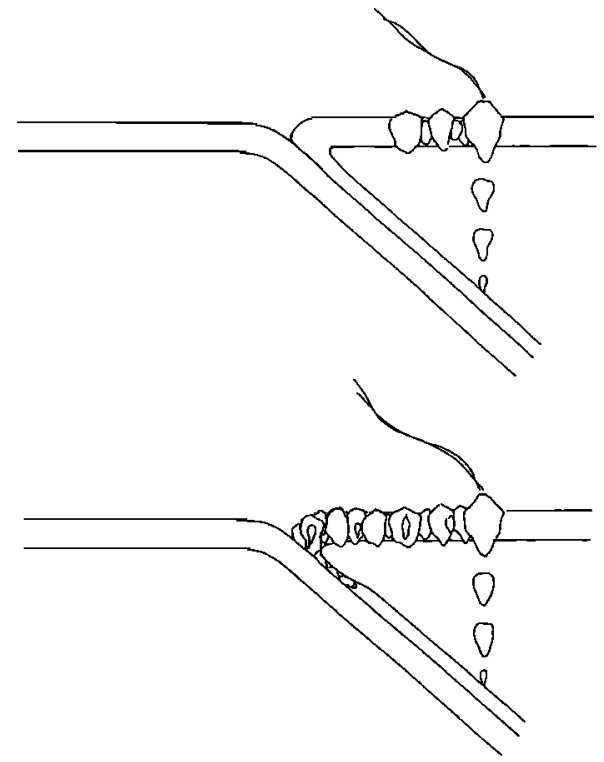

Fig. 17. Slowing of Marianas-style ablation over time: as ablation proceeds, island arc material is gradually emplaced within the forearc (Figures 17a and 17b) [after Bloomer, 1983]. When this island arc material enters the trench (Figure 17c), its buoyancy should reduce or inhibit the rate of ablation.

subsiding as they cool. This process will gradually replace the initial oceanic forearc with one composed of island arc basement. (The most recently erupted rocks will then lie near the active arc while the oldest will be found close to the trench.) As this basement will be both warmer and compositionally less dense than the original oceanic forearc, its entry into the trench should reduce the rate of ablation.

Just such a progression seems to have taken place in the Marianas. Deep Sea Drilling Project (DSDP) drillings and 
seismic studies of the Marianas forearc indicate that it is composed of island arc basement [Meijer, 1980; Hussong et al., 1978; Bloomer and Hawkins, 1980; Latraille and Hussong, 1980], upon which lie many large seamounts of possibly igneous origin [Hussong and Uyeda, 1980]. This arc-derived basement shows the expected age progression of increasing age toward the trench, with early Oligocene rocks lying midbasin [Mrozowski and Hayes, 1980], and an Eocene arc complex appearing within the trench wall itself [Bloomer, 1983]. Moreover, the modern Marianas arc overlies young back arc basin material (Figure 16), a geometry that can result only from a rearward displacement of arc volcanism. (Elsewhere, the Scotia (South Sandwich Islands) and Tonga subduction zones are similarly sited [Barker and Hill, 1981; Weissel, 1981], and the West Marianas Ridge, a former site of Marianas arc volcanism, also lies atop the rifted forearc of the older Palau-Kyushu Ridge [Taylor and Karner, 1983].) The character of the Marianas arc and forearc is thus consistent with the occurrence of ablation in the past. In turn, a recent slowing or cessation of ablation is suggested by evidence of accretion in the southern part of the Marianas [Karig and Ranken, 1980], by the survival of arc material dating back more than $32 \mathrm{~m} . \mathrm{y}$. in the nearby islands of Guam and Palau [Meijer, 1980], and by signs that forearc consumption in the middle Marianas took place primarily between 42-45 m.y. and 25-30 m.y. ago [Bloomer, 1983]. Additionally, we note that the zone's current $200-\mathbf{k m}$ arc-trench gap is unusually wide [Karig and Ranken, 1980] and that the underlying slab profile is much flatter near the Earth's surface than it is at depth (Figure 8 [Jarrard, 1986]). Such characteristics can result from a decrease in ablation (and/or an increase in back arc spreading), for the consequent increase in effective trench migration will lead to a shallowing of the upper slab.

Within the ablative model, we would therefore ascribe the shape of the modern Marianas slab to fairly vigorous ablation in the past (which will have given the profile its overall steep dip) and to a more recent slowing or cessation of forearc consumption serving to flatten the near-surface part of the profile. Additionally, if a given Marianas-style subduction zone is fairly young, then some of the slab's steepness might be a holdover of its youth (Figure 7), with ablation helping to slow the slab's evolution toward an increasingly shallow shape.

What is not clear is whether ablation in the Marianas itself was ever strong enough to maintain a stable, steep slab profile. Estimates of Marianas forearc consumption rates range from a steady $0.15-0.3 \mathrm{~cm} / \mathrm{yr}$ [Beccaluva et al., 1980] to a $0.3-0.5 \mathrm{~cm} / \mathrm{yr}$ pulse of $12-20 \mathrm{~m} . \mathrm{y}$ duration [Bloomer, 1983]. Compared with the modern Marianas convergence velocity of some $8-10 \mathrm{~cm} / \mathrm{yr}$ [Fryer et al., 1990], such rates are much lower than what our experiments suggest is required to produce steep, mature slabs. While convergence velocities might have been lower during the height of the ablative pulse (if, for example, the ablation took place during a period of inactive back arc spreading) and while our experiments probably overstate the required degree of ablation by not including the effect of other slab-steepening mechanisms, it seems unlikely that such a weak rate of ablation can of its own maintain a steep slab. If these estimates represent the maximum amount of ablation in the Marianas forearc, we would therefore suggest that ablation's chief role has been to help retard flattening of the slab profile.

Alternatively, it is conceivable that current consumption estimates, which are based on patterns of surviving arc base- ment, underestimate the peak rates of ablation. If arc material eventually enters a trench, then we will have lost all record of both subduction and ablation at the time of the arc's creation. Thus vigorous ablation will tend to remove evidence of its occurrence. Such a consumption of arc material might be used to explain why arc age estimates vary widely between continental and oceanic arcs: when we compile arc ages (taken from Jarrard [1986]) by subduction type, we see that continental volcanic arcs are typically several times older than their oceanic counterparts (Table 2). If arc ages are used to constrain the duration of subduction, as they are typically used within the classical subduction model, this pattern is not easily explained. The remarkable youth of many oceanic zones may reflect a greater ease of subduction initiation in oceanic regions, but it is curious that even the oldest oceanic zones are comparatively young. Possibly, oceanic subduction is simply short-lived, but there is no obvious reason why the presence of a continent should so emphatically increase subduction duration. Indeed, given the apparent resistance to subduction displayed by Andeanstyle slabs, one might expect the opposite correlation between duration and crustal type.

TABLE 2. Arc Ages

\begin{tabular}{lr}
\hline \multicolumn{1}{c}{ Trench } & Arc Age, m \\
\hline \multicolumn{2}{c}{ Continental Zones } \\
Columbia & 242 \\
Chile & 226 \\
Ecuador & 226 \\
Peru & 226 \\
Cascades & 175 \\
SW Japan & 175 \\
Alaska & 160 \\
Alaska Peninsula & 160 \\
Kamchatka & 153 \\
T. del Fuego & 150 \\
NE Japan & 115 \\
Andaman & 100 \\
Mid. America & 100 \\
Mexico & 90 \\
Kurile & 82 \\
Ryukyu & 55 \\
Makran & 46 \\
Sumatra & 27 \\
New Zealand & 21 \\
Aegean & 11
\end{tabular}

Oceanic and Transitional

$\begin{array}{lr}\text { Central Aleutians } & 56 \\ \text { Lesser Antilles } & \mathbf{4 8} \\ \text { Marianas } & 45 \\ \text { Izu-Bonin } & \mathbf{4 5} \\ \text { Palau } & 45 \\ \text { Yap } & 45 \\ \text { Kermadec } & 30 \\ \text { Scotia } & 30 \\ \text { Java } & 27 \\ \text { Tonga } & 24 \\ \text { Sangihe } & 13 \\ \text { New Britain } & 8 \\ \text { New Hebrides } & 8 \\ \text { Solomon } & 8 \\ \text { North Sulawesi } & 7 \\ \text { Philippine } & 6\end{array}$

From Jarrard, 1986. Oceanic arcs are generally much younger than arcs on continents; this age distribution is consistent with an ablative recycling of island arc material. 
If, however, arcs can be entirely consumed, then the youth of modern oceanic arcs does not imply a corresponding youth of subduction. Episodes of vigorous ablation would then remove records of ancient subduction, biasing arc ages toward anomalously low values. Such a consumption would explain the curious nature of the North Sulawesi slab: while the arc-derived age of subduction in North Sulawesi is $7 \pm 4$ m.y., the tip of the slab appears to have been subducted some 15.3 m.y. ago [Jarrard, 1986]. Assuming these estimates are not grossly in error, they would suggest that geologic evidence for the earliest phase of North Sulawesi subduction has been lost.

Arc consumption would also help explain why apparent hiatuses are found in the arc magmatism of Marianas-style areas. For example, arc volcanism in the Marianas zone seems to have been minimal between $20 \mathrm{Ma}$ and $30 \mathrm{Ma}$, with another gap appearing from 5 to $9 \mathrm{Ma}$ [Scott and Kroenke, 1980]; likewise, a minimum in Ryukyus volcanism has also been reported for the period 21-49 Ma [Bowin and Reynolds, 1975]. Within the framework of the classical model, the origin of these gaps is unclear. Because the minima often coincide with pulses of back arc spreading, it has been suggested that back arc spreading and arc volcanism are inherently asynchronous processes [Scott and Kroenke, 1980]. However, this suggestion conflicts with the synchroneity of spreading and arc volcanism that is displayed by more modern back arc spreading regions [Karig, 1980]. Ablation can reconcile these conflicting observations: if arc magmatism is continuous, episodes of vigorous ablation, perhaps linked in some fashion to back arc spreading, might produce apparent gaps in the record.

If ablation can be episodic, then we have an alternative explanation for the steepness of Marianas-style slabs. It is conceivable that these slabs neither remain stable nor become monotonically more shallow with time; instead they might flatten and steepen with alternate periods of accretion and ablation. Such an episodicity must remain speculative until more experiments are performed, but its occurrence at least seems possible. We have proposed that Marianasstyle ablation will be self-limiting, as over time the forearc basin will incorporate buoyant masses of warm arc-derived basement. This suggestion is consistent with observations of anomalously high and variable rates of heat flow in the fore-arc basins of East and Southeast Asia [Anderson, 1980]. Of interest is what happens when this forearc cools, for with cooling will come a rise in plate density. Resurgent ablation may then consume the arc-derived forearc, induce a temporary steepening of the slab, and perhaps even accentuate back arc spreading by increasing tensile stresses within the overriding plate. Eventually, this resurgence will also foster a renewed migration of the arc, and a warm, arc-derived forearc might then redevelop to start the cycle anew. Thus ablation in Marianas-style subduction zones is potentially complex in its effects, and the ablative model allows for dynamic feedbacks relating slabs to arcs, forearcs, and back arc spreading basins.

\section{Ablation in Philippine-Style Subduction Zones}

We would expect ablative subduction to adopt its most extreme form when plates of similar character converge in a compressional tectonic regime. Such plates would be ex- pected to lack both the inherent asymmetry of Andean subduction and the extension-influenced, intermediate character of Marianas-style zones. Plate consumption might then take place in a symmetrical fashion, producing surface effects that are difficult to interpret within the framework of classical one-sided subduction. A possible example of such a region is the tectonically complex area about the Philippine Islands.

In an ablative convergence of symmetrical plates, the lower lithosphere should descend as a simple, near-vertical downwelling (Figure 4a). If such a slab yields arc volcanism, magma originating in the slab will tend to rise through or near the center of the convergence zone, accumulating at the surface as a centrally located island arc. This linear, buoyant mass may be further augmented by continental or arc material brought in from elsewhere. Because such an arc will be kept warm by active volcanism, and because it will not suffer the rifting that occurs in extensional zones, it should be more likely to survive than its Marianas counterpart. By accumulating in the center of the convergence, this arc may then considerably complicate the surface response to an essentially simple ablative downwelling.

The simplest geometry is that of double subduction, whereby a central landmass is bounded on either side by converging subducting plates. Examples of such double subduction might be found in the Philippines [Rangin et al., 1988] and Caribbean [Larue, 1989], and its occurrence is also consistent with the occurrence of anomalous seismicity behind Costa Rica (G. Ekström, personal communication, 1991) (Figures 18a-18c).

A second possibility is that of time-varying subduction, in which subduction appears to oscillate about a centrally located arc. The mechanism behind such an oscillation is shown in Figure 19. If for some reason the upper lithosphere fails in an initially asymmetric fashion, a single trench will form to one side of the central landmass (Figure 19a). Hence, while ablation removes the lower lithosphere in a roughly symmetric fashion, the surface appearance is that of a conventional one-sided subduction zone. Because of this surface asymmetry, the arc will try to migrate toward the apparent subducting plate. This movement will carry the active trench away from the vertical axis of the vertical slab, and the top of the slab will come to lie beneath the inactive side of the arc (Figure 19b). If ablation-induced stresses then cause the overlying plate to fail, subduction will appear to wane on one side of the arc while strengthening on the other (Figure 19c). In this way, subduction will have apparently changed direction, with a brief appearance of double subduction in the shift from one polarity to the other. Such a process would be consistent with the observation that most recently reversed arc systems are associated with extremely steep slabs [Karig, 1972], and it suggests a mechanism for spontaneous reversals of subduction polarity that does not require an arc or continent collision to have occurred. (As noted earlier, a spontaneous reversal seems to have taken place about the Philippine island of Luzon [Lewis and Hayes, 1980].)

A third possibility is again of subduction reversal, the reversals occurring in straightforward response to changes in rates of ablation. If the asymmetry of plate density changes over time, through either arc collision or a more gradual alteration of plate character, then a simple redistribution of 


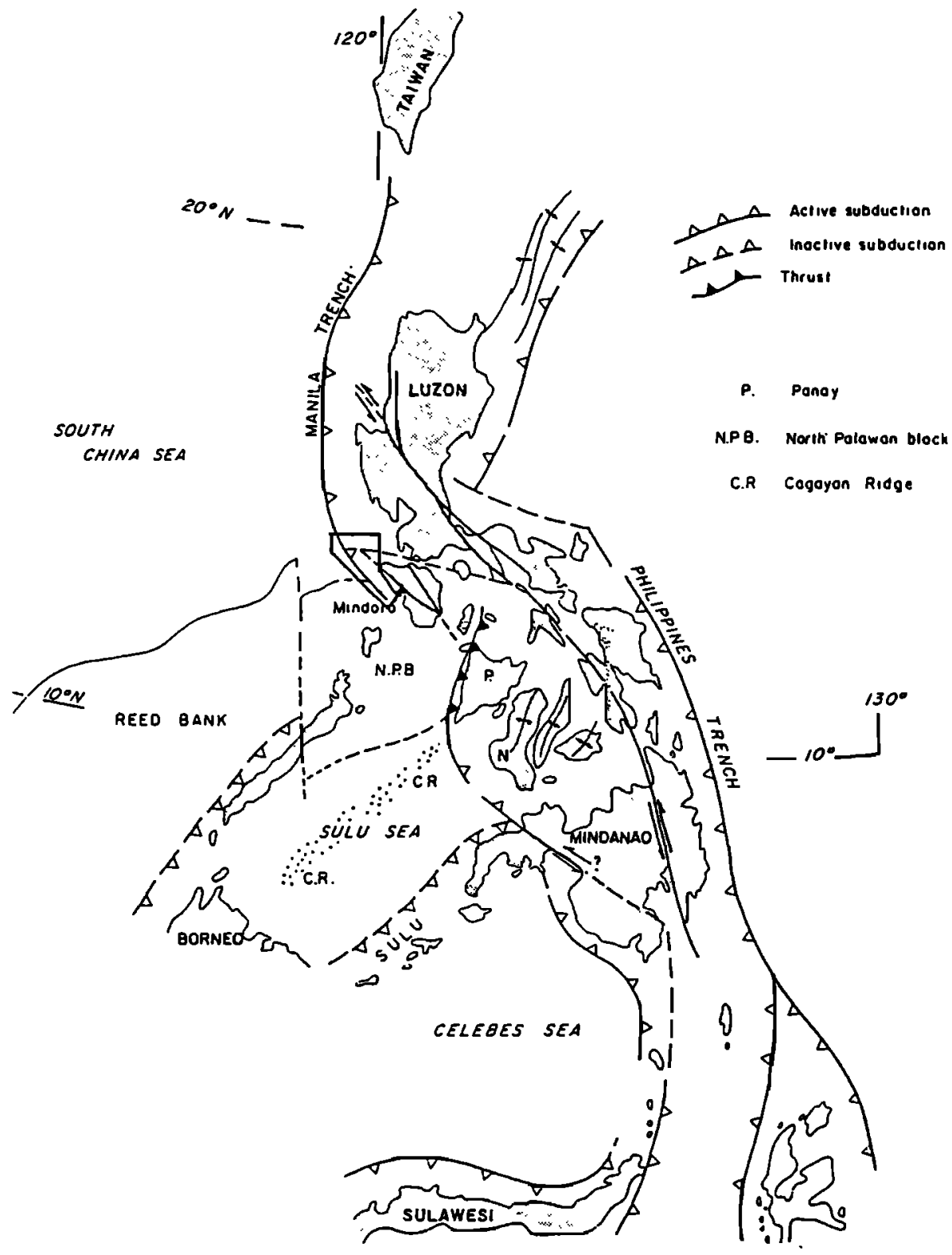

Fig. 18a. Double subduction. Proposed tectonics in the Philippines, showing linear island chains bounded on either side by subduction [from Rangin et al, 1988].

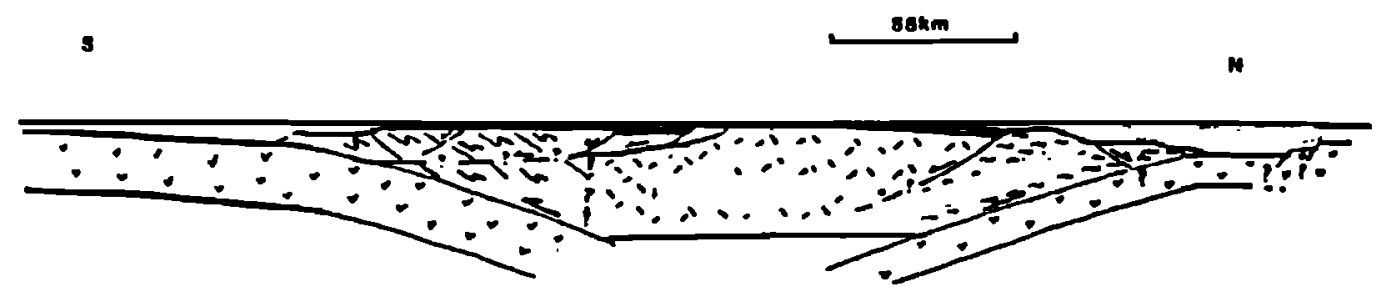

Fig. 18b. Proposed cross section across the Mona Passage, near Puerto Rico [after Larue, 1989].

relative ablation rates may suffice to "swing" a slab from one polarity to the other (Figure 20a). If this swinging of the slab occurs at different times along different sections of the trench, then a single trench will appear to overlie two adjacent slabs of opposite polarity. Such a slab geometry has been proposed in the Molucca Sea south of the Philippines (Figure 20b [after Addicott and Richards, 1981]). The conventional explanation for this feature would be that two 


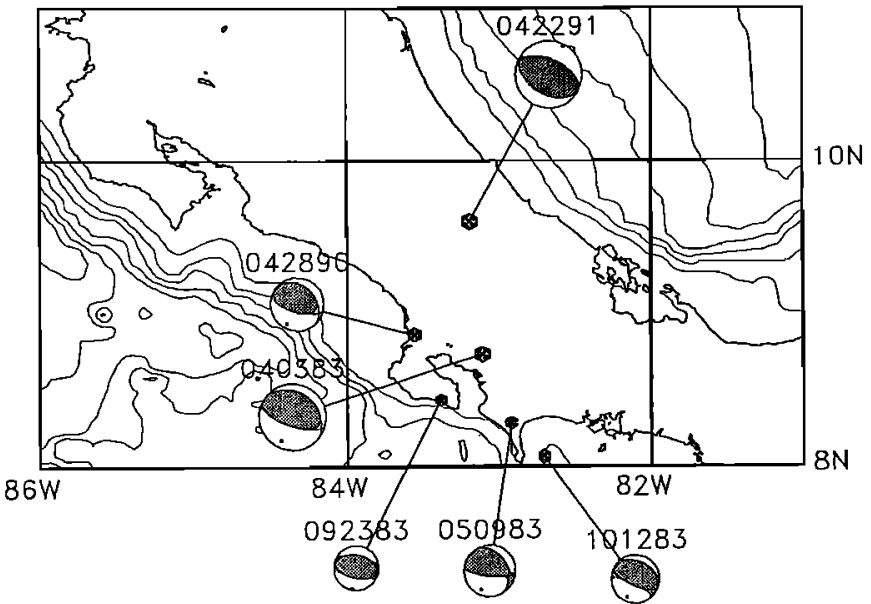

Fig. 18c. Anomalous earthquake beneath Costa Rica. Earthquake 042291 lies above the plane of the slab and may be interpreted as indicating a shallow thrusting from the north (G. Ekström, personal communication, 1991).

oppositely migrating subduction zones have passed by each other; an explanation in the ablative framework would be that what appears to be two slabs is in fact a single downwelling that has not wholly reversed its dip.

Thus in addition to double subduction, the ablative model allows for two dynamically plausible modes of subduction polarity reversal. In both mechanisms, the lower lithosphere smoothly descends while the upper lithosphere responds discontinuously. Given the apparent frequency of subduction reversals, this aspect of the model is a significant strength. Within an ablative framework, we can interpret complex tectonic processes as a response of the Earth's brittle surface to simple viscous ablation below; this conceptual decoupling between surface and interior is a major distinction between the ablative and classical models. In the classical model, we must directly relate what we see at the surface to processes and geometries deep underground. This requirement causes complications when we consider complex tectonics (Figure 2, repeated as Figure 21a), complications that disappear when we relax the conceptual link between surface and interior (Figure 21b).

\section{Conclusions}

We see that an alternative view of subduction, one based on the viscous consumption of the lower lithosphere, is an appealing way of modelling the majority of the Earth's convergence zones. If we consider subduction not as an overlapping and sliding of rigid plates, but as a process more akin to the downwelling of a convecting fluid, then we can easily and simply explain variations in slab shape, interplate seismicity, observations of tectonic erosion, double subduction, and subduction reversal, all with a single, simple model. While these phenomena and observations can also be explained within the classical framework, the required mechanisms are often less elegant. For dynamical reasons, we suggest that classical subduction best applies to regions like the Aleutians (i.e., those areas in which overriding plates are strong enough to control the subduction process). In the remaining convergence zones, which are far more numerous, subduction may be ablative, with the lower lithosphere falling away as
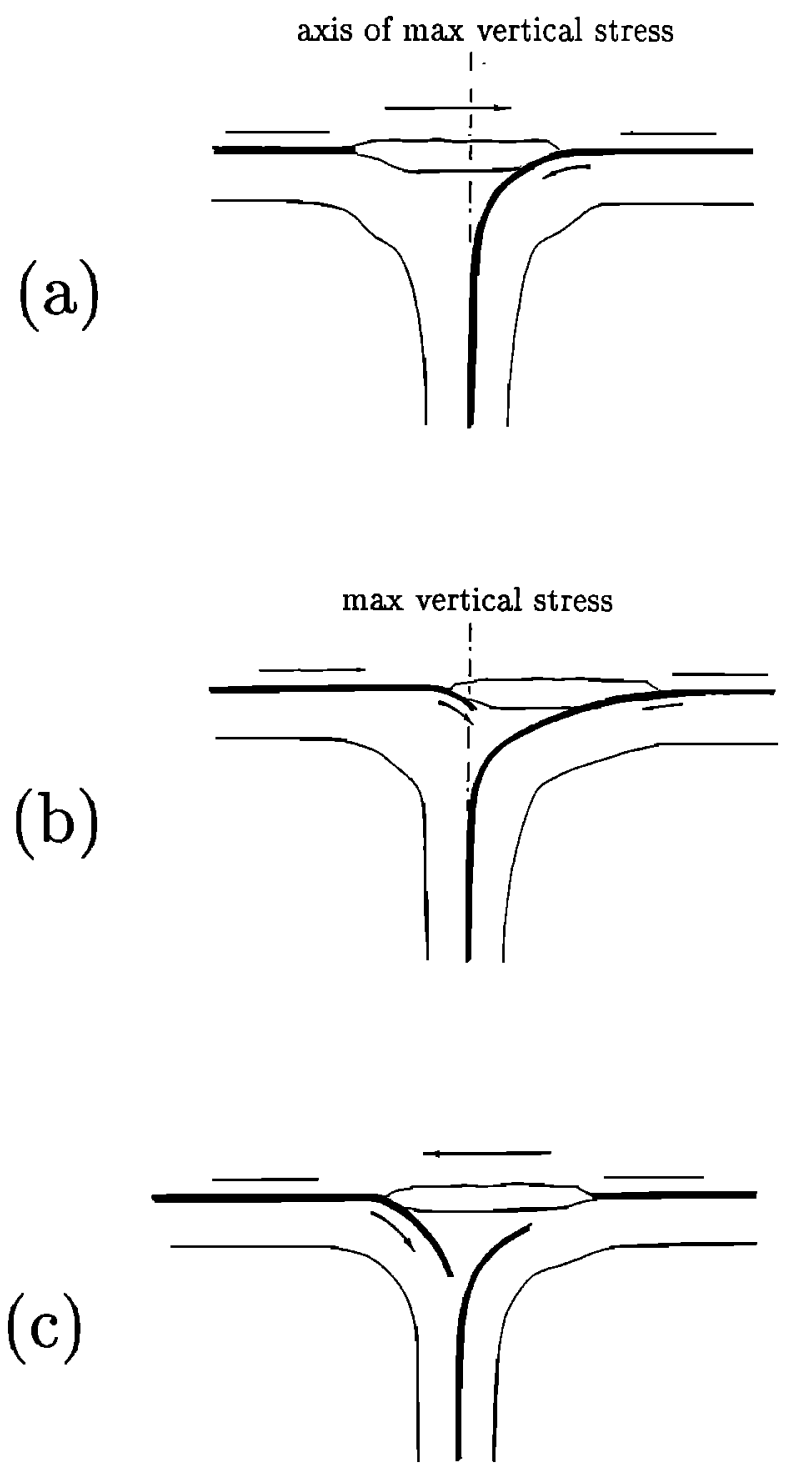

Fig. 19. Apparent reversals in subduction polarity: a nearsymmetrical, vertical "slab" exerts a downwards pull on the material directly above it; if this pull can break the elastic lithosphere and crust, an island arc may oscillate about the axis of the slab. (a) An arc bounded by a single trench will move toward the apparent subducting plate. This motion puts the passive side of the arc over the slab, where vertical slab-induced stresses are highest; (b) plate failure might then create a transient stage of double subduction. (c) As the new trench experiences higher stresses than does the original, subduction may then appear to undergo a spontaneous change in polarity. At all times, subduction of the lower lithosphere proceeds simply and smoothly.

a fluid and the more brittle surface layers then breaking up to suit.

An integral aspect of the ablative model is that it allows for a two-sided mode of lithospheric descent. While some loss of overriding plate material has long featured in geochemical models as a means of recycling continental crust into the mantle [Gilluly, 1971; Jacobsen, 1988], such "tectonic erosion" has generally been considered dynamically unimportant. We suggest that ablative losses of the viscous lithosphere may at times be significant, and that these losses may influence the evolution of a subducting slab's profile. 


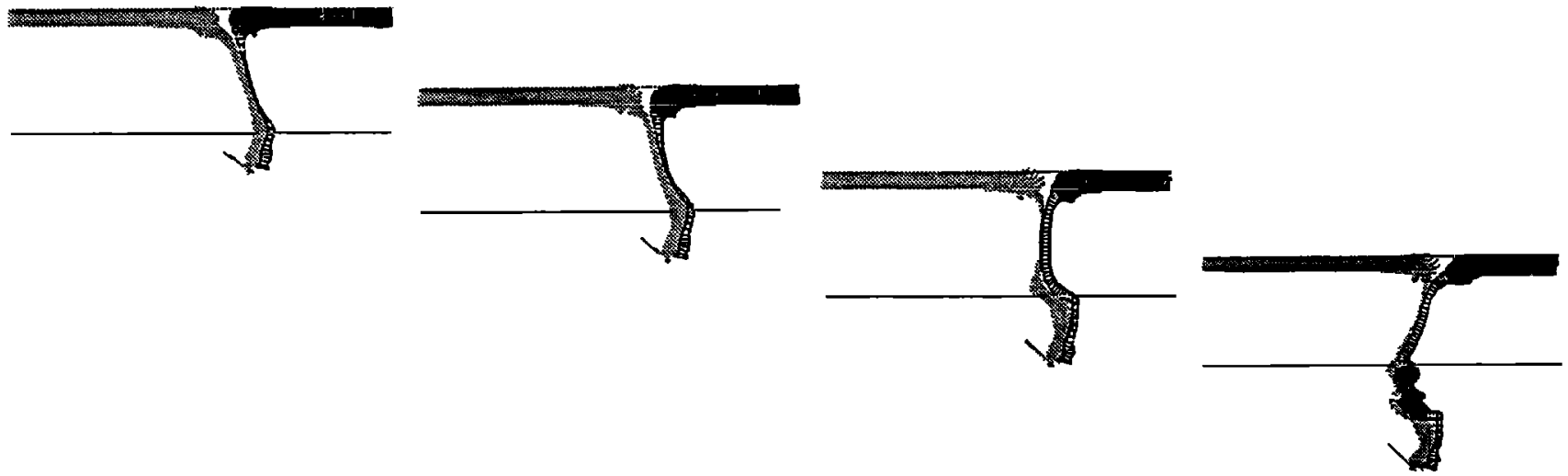

Fig. 20a. Subduction reversal through changes in ablation rate: a stable subduction zone with $\alpha=0.333$ has its ablation rate suddenly upped to $\alpha=0.667$, reversing the dip of the slab.

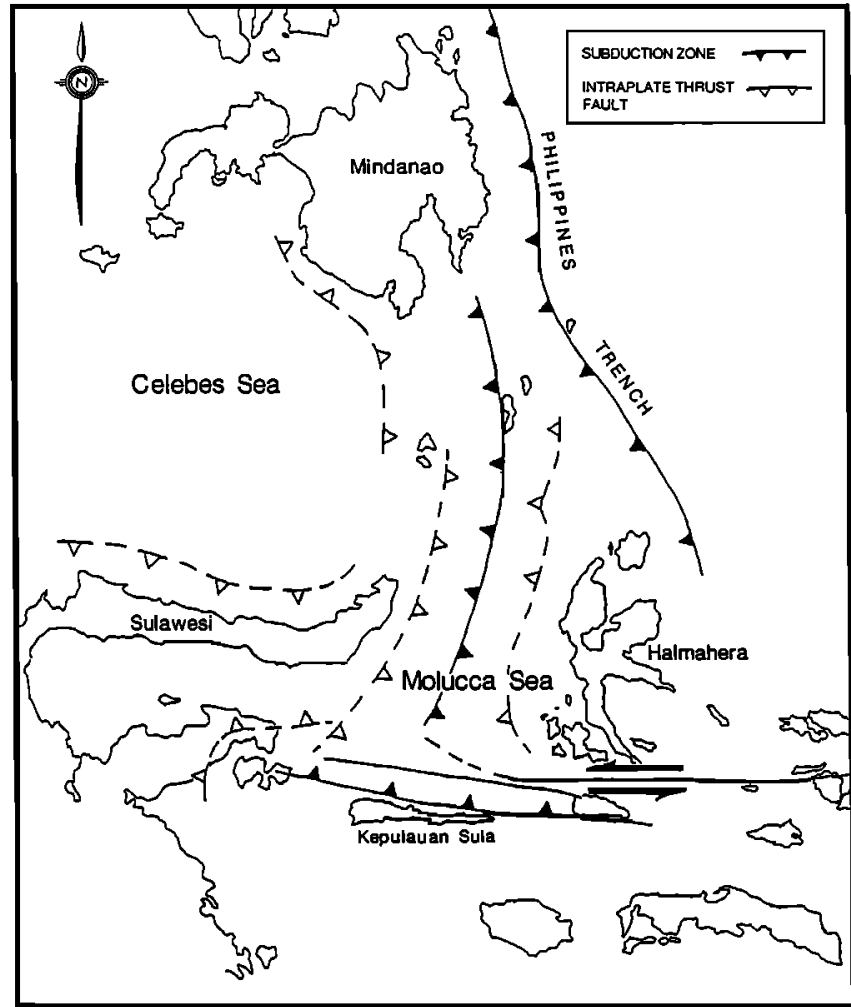

Fig. 20b. Proposed plate boundary in the Molucca Sea south of the Philippines: the north-south trench between Sulawesi and Halmahera shows a slab reversal from west dipping near Mindanao to east dipping farther south near Kepulauan Sula [after Addicott and Richards, 1981].

The slabs within the ablative model are not slablike in a rheological sense. Instead, we assume their behavior to be predominantly that of a fluid. Our experiments show that slab strength is not necessary to explain the shapes of seismic Benioff zones. Even completely fluid downwellings can take on realistic shapes, particularly if plate consumption can at times be double-sided. In Andean-style regions, where continental buoyancy inhibits ablation of the overriding plate, subduction can be approximately one-sided. Rapid effective trench migration will then encourage the gradual development of a flat-lying, kinked slab. With higher ablation rates, as should occur in oceanic zones, effective trench migration will be hindered. The progressive flattening of a slab is thus slowed, and steep profiles can be stable when moderate ablation occurs. In addition, the pattern of deformation undergone by fluid slabs, be they ablative or one-sided, is consistent with frequently observed seismic focal mechanisms if the mantle's viscosity increases below $670 \mathrm{~km}$ : at the surface is compression, at intermediate depths there is extension, and at the bottom of the upper mantle there is again compression. Buoyancy-controlled ablative subduction can thus account for many fundamental characteristics of oceanic and continental-style slabs.

If ablative subduction does occur in oceanic regions, it might not be readily discerned through patterns of seismicity. In the lithosphere and uppermost mantle, the deformation associated with moderate ablation is consistent with observed seismicity patterns, while at greater depths, ablated material adheres closely to the downgoing slab and might not be easily resolved. The relative aseismicity of Marianas-style convergence, however, is consistent with the ablative model: if ablation occurs here, then a rolling under of forearc basins might allow even seismically coupled plates to converge aseismically.

What should control the character of an ablating oceanic subduction zone is the region's overall tectonic regime. In an extensional regime, ablation is self-limiting, and subduction might go through cycles of accretion and moderate ablation. (If such cycles occur, then the consumption of arc material might destroy evidence of previous phases of subduction and ablation.) With compression, the convergence of oceanic plates can lead to vigorous ablation, double subduction, and observations of apparent subduction reversal. In each case, the behavior of the lower lithosphere is relatively simple; what varies is the rate of ablation and the response of the upper lithosphere.

Thus, while ablation is not easily proven, its incorporation into a model of subduction can simplify the interpretation of conflicting and complex observations. It suggests a unified model for almost all convergence zones, is consistent with modern views of a partly fluid lithosphere, and elegantly explains slab profile variations and various problematic surface processes. The model thus invites further exploration to determine its range of applicability, its limitations, and its implications. 

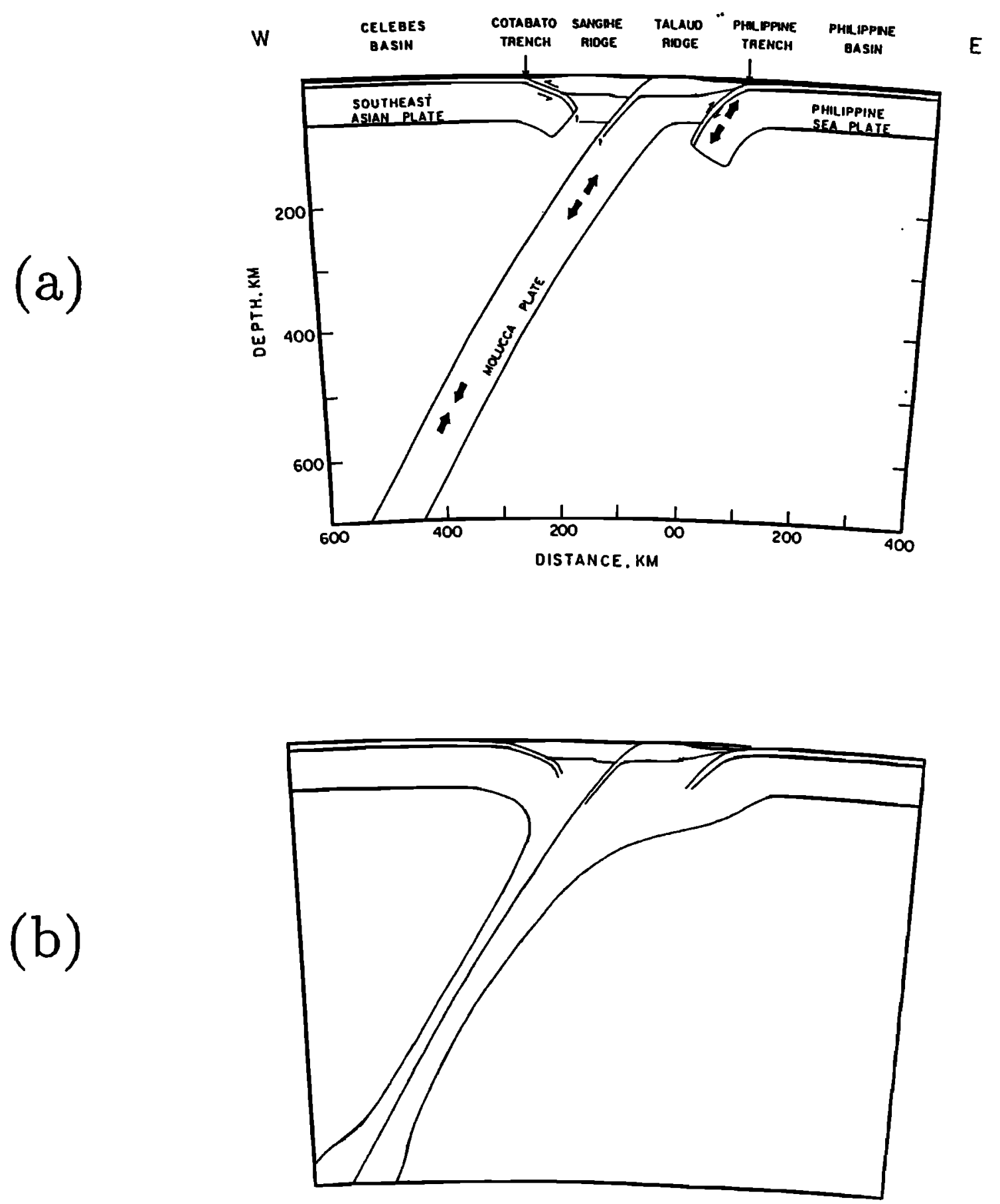

Fig. 21. (a) Classical interpretation of slab profiles south of Mindanao, Philippines [from Cardwell et al., 1980]; repeated from Figure 2. (b) An example of an ablative interpretation of the same region.

\section{APPENDIX A: EXPERIMENTAL MODEL}

In our numerical experiments, subduction is modelled as the foundering of dense material. These experiments are essentially experiments in fluid flow, in that the sinking of slab material drives internal flow within the mantle, and the mantle flow in turn drives the surface plates and distorts the slab as it sinks.

Ideally, our experimental model would incorporate detailed rheologies and forces identical with those in real subduction zones, but in practice, the properties of plate, slab, and mantle are themselves the subjects of active research and are not at all certain. Rather than base our experiments on a particular view of the Earth, we instead adopt a more neutral, simple model, wherever possible choosing experimental parameters that will best illustrate ablative effects. The greatest simplifications involve the rheologies of the plates and slabs and the number of forces driving the plates. Since internal strength will hinder a slab's response to changing stresses, we model slabs as fluid downwellings which differ from the mantle solely through their greater density. In effect, our slabs are so broken in the process of subduction that they cannot resist the effects of mantle 
flow. While real slabs are likely to be more viscous and hence stronger than surrounding material [Zhang et al., 1985], the rheology we use maximizes a slab's response to changes in the mantle flow field that may arise from migration. Such a rheology is also consistent with the very seismicity of slabs, which indicates that they deform as they descend, and with both modelling considerations [Hager and O'Connell, 1978; Bevis, 1986] and detailed studies of slab morphology [Giardini and Woodhouse, 1984, 1986; Fischer et al., 1988], which suggest that a slab's strength does not prevent its being sculpted by mantle flow. As it is not clear how much of a slab's observed profile is governed by its internal strength and how much by fluid flow, our study then has the additional goal of determining to what extent flow effects alone may account for slab shape. For the lithospheric plates, we adopt the standard division of the lithosphere into elastic and viscous portions [Jordan, 1978] and model the viscous lower portion as a layer of high-viscosity fluid atop the mantle. Rather than explicitly include the elastic upper portion, we impose a platelike velocity boundary condition on the flow atop the viscous lithosphere; this condition mimics the nonlinear behavior of a rigid upper lithosphere strong enough to maintain platelike motion within plate interiors but weak enough to fail abruptly at the boundaries. So that flow beneath the trench is not distorted by arbitrarily chosen plate velocities, we set the surface velocities to reflect the motions of plates that are driven by the flow surrounding a sinking slab. This choice of dynamically consistent plate velocities forms the third major simplification in the model, in that we neglect potentially significant plate forces such as ridge-push/lithospheric-thickening, which will drive the plates faster, and collisional resistance, which will slow them.

The model we use is shown in Figure A1. Its geometry is two-dimensional Cartesian, with periodic sidewalls, a platelike surface boundary condition at the top, and a freeslip condition representing the core-mantle boundary at the bottom. Within this periodic box, a Newtonian viscous fluid represents material of the upper mantle, the lower mantle, and the viscous portion of the lithosphere. In the present experiments, we scale the box to span $2900 \mathrm{~km}$ in the vertical direction and $5800 \mathrm{~km}$ in the horizontal; flow is evaluated on a grid numbering 65 points across and 33 down, yielding an effective spatial resolution of about $90 \mathrm{~km}$. Viscosity transitions at depths of $90 \mathrm{~km}$ and $670 \mathrm{~km}$ distinguish the

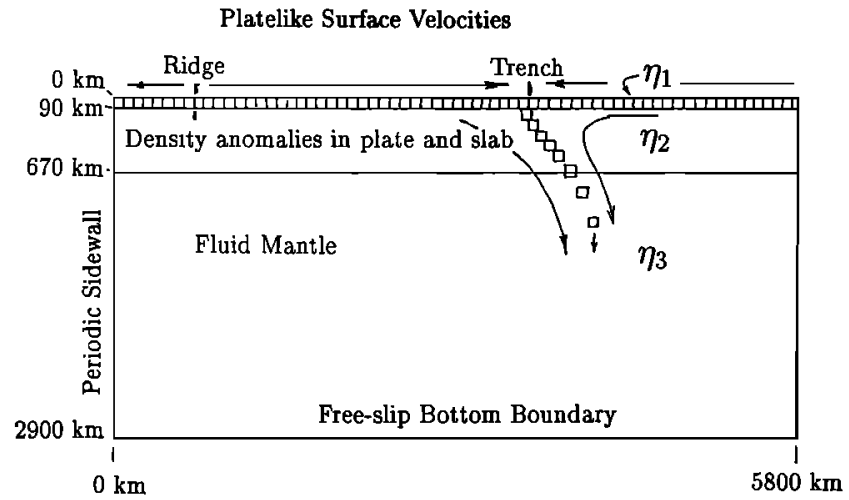

Fig. A1. Geometry and rheologies used for numerical experiments. $\eta_{1}=10 \eta_{2}$ in all experiments. In the first set of experiments, $\eta_{3}=\eta_{2} ;$ in the second set, $\eta_{3}=10 \eta_{2}$. lithosphere from the upper mantle and the upper from the lower mantle (material may freely pass through the transitions). In all the experiments, the lithospheric viscosity is 10 times that of the upper mantle (higher lithospheric viscosities do not produce significantly different results). The fluid associated with the lithosphere is of usually of higher density than fluid belonging to underlying regions; in the first experimental set, we set the lithosphere lying to one side of the trench at different relative densities, while in the remaining experiments the lithosphere has a constant density throughout. As this dense lithospheric fluid sinks, it generates a flow field through the entire box. To determine its path of descent, we make use of what is normally a numerical limitation: because a computational scheme cannot distinguish between mass concentrated at a point and mass distributed within the model's spatial resolution limit, the flow generated by a continuous dense fluid is indistinguishable from that generated by closely spaced point masses. We therefore treat the high-density lithosphere as a collection of point density anomalies, each anomaly representing the excess mass of a region of cold lithosphere. In its initial state, our model thus contains a row of evenly spaced, uniform point anomalies, all lying $45 \mathrm{~km}$ below the surface of the fluid. From these density elements, we calculate the flow field using a quasi-analytic method discussed in Appendix $B$, then use the flow field to advect the anomalies through successive time steps.

Our experiments proceed as follows: starting with the uniform row of lithospheric anomalies, we select initial positions for a ridge and a trench. At the trench, we perturb a single anomaly downward to initiate subduction, then step the model through time by following a simple set of instructions (Appendix B): with each time step, we calculate the flow field generated by the density anomalies (Appendix B), paying due attention to density-driven motions of the surface plates (Appendix C); anomalies are then advected to new positions along the streamlines. From the surface plate velocities, we determine the migration speeds of the ridge and trench: the ridge moves at the vector average of the plate velocities (the condition for symmetrical spreading), the trench in accordance with equation (1); these migration velocities are used to shift the ridge and trench in preparation for the next time step. (In the first experimental set, $\alpha$ is determined by measuring the flux of material that passes through a horizontal plane lying one grid level beneath the base of the viscous lithosphere; in the second, we specify the value of $\alpha$ for each run.) Finally, if anomalies have moved apart at the ridge, we emplace new (constant-magnitude) anomalies to represent the production and fast cooling of fresh lithosphere.

The simplicity of the instruction set points out an important aspect of our model: after the initial, single displacement that begins subduction, the density anomalies freely advect without further guidance. No attempt is made to force them downward at the trench, to pin them to the surface elsewhere, or to force them to move together as a plate or slab. Platelike motion comes from the velocity boundary condition, which in practice tends to entrain anomalies in a near-surface horizontal flow; if an anomaly does begin a descent, it is because it has encountered a downwelling in the overall flow field (in practice, such downwellings occur where plates converge). At all times, anomalies are mechanically independent of one another, and the "slabs" they form are 
effectively nothing more than regions of strengthless dense fluid, freely moving with the vagaries of mantle flow. Collectively, these anomalies show the development of simple, easily deformed slabs beneath migrating trenches; by running the experiment with varying values of $\alpha$, we may see how ablation can influence the course of that development.

\section{APPENDix B: Structure of THE Numerical Code}

We solve for the flow field in a sequential manner. In the initial time step, all density anomalies but one lie in a uniform sheet near the top of the fluid; the remaining anomaly is displaced downward at the trench to initiate subduction. We calculate the flow (Appendix C) that these anomalies would generate when placed under a zero-velocity top boundary; this flow field is stored, and the shear tractions at the base of the viscous lithosphere are used to determine dynamically consistent plate velocities (Appendix D). The plate velocities are then used in a second calculation, in which we determine the flow produced by plate motions in the absence of density anomalies. Adding the density-driven and plate-driven flow fields together gives us the complete flow field.

Our next step is to advect the anomalies through the flow field. We determine the streamlines passing through each anomaly and move the anomalies along them. This advection proceeds until the fastest moving anomaly has travelled a distance equivalent to half a grid spacing, at which point the advection is halted until a new flow calculation is performed. Each time step is therefore of variable length.

Last, we use the dynamically consistent plate velocities to determine the trench and ridge migration velocities: the ridge travels at the vector sum of the plate speeds, while the trench velocity is given by equations (1) and (2) in the text. We assume that plate speeds remain constant within a time step and simply multiply the migration speeds by the duration of the time step to obtain the new plate boundary positions.

\section{ApPendix C: Mathematical Development}

\section{Analytic Solution}

We calculate fluid flow by combining an analytic propagator solution with a numerical finite difference scheme. The analytic development closely follows that used by Hager and O'Connell [1981], with a few changes to increase the flexibility of the solution, while the numerical part of the method involves a modification of a standard relaxation code.

The flow in our experiments takes place in two dimensions and is assumed to be periodic along the horizontal axis, with a spatial wavelength of $L$. For flow in an incompressible Newtonian fluid at zero Reynolds number, the governing equations are the continuity equation, the constitutive equation, and the equations of motion:

$$
\begin{gathered}
\nabla \cdot \mathbf{v}=\mathbf{0} \\
\tau=2 \eta \dot{\epsilon}-p \mathbf{I} \\
\nabla \cdot \tau+\mathbf{f}=\mathbf{0}
\end{gathered}
$$

where $\mathrm{v}$ is the fluid velocity, $\tau$ is the stress tensor, $\eta$ is the viscosity, $\dot{\epsilon}$ is the strain rate tensor, $p$ is the nonhydrostatic pressure, $I$ is the identity matrix, and $f$ is the vertical body force $\Delta \rho g$ arising from a density perturbation $\Delta \rho$ under gravitational acceleration $g$.

To solve these equations, we express fluid stresses and velocities as the real part of a discrete Fourier series:

$$
f(x, z)=R e \sum_{n=0}^{N} f_{n}(z) e^{i k_{n} x}
$$

where $x$ is the horizontal axis; $z$ is the vertical, with $z=0$ at the top of the fluid and $z=1$ at the bottom; $k_{n}$ is the wavenumber, given by $k_{n}=2 \pi n / L ; N$ is the maximum number of terms retained $(N=32$ in the present experiments); and $f(x, z)$ is either the vertical velocity $v_{z}$, the horizontal velocity $v_{x}$, an element of the nonhydrostatic stress tensor $\tau_{i j}$, the nonhydrostatic pressure $p$, or a density perturbation $\Delta \rho$. Finding the solution to equations (A1)-(A3) then becomes a matter of solving for the Fourier coefficients $f_{n}(z)$.

Following the method of Hager and O'Connell [1981], we combine equations (A1)-(A4) into a vector equation for each fourier mode:

$$
\frac{d \mathbf{u}}{d z}=\mathbf{A u}+\mathbf{b}
$$

where $\mathbf{u}$ is the array $\left[u_{1}, u_{2}, u_{3}, u_{4}\right]^{T}$, given by

$$
\begin{aligned}
u_{1} & =-i k v_{z} \\
u_{2} & =k v_{x} \\
u_{3} & =-\frac{i}{2 \eta_{0}} \tau_{z z} \\
u_{4} & =\frac{1}{2 \eta_{0}} \tau_{x z}
\end{aligned}
$$

b is the array $\left[0,0,-i \Delta \rho g / 2 \eta_{0}, 0\right]^{T}$ for each of $m$ density anomalies, of vertical thickness $\Delta \gamma$ and located at depth $\gamma$, and $A$ is the matrix

$$
\mathbf{A}=\left[\begin{array}{cccc}
0 & -k & 0 & 0 \\
k & 0 & 0 & 2 k / \eta^{*} \\
0 & 0 & 0 & -k \\
0 & 2 \eta^{*} k & k & 0
\end{array}\right]
$$

with $\eta^{*}=\eta / \eta_{0}$, and $\eta_{0}$ as some reference viscosity. The solution is then

$$
\mathbf{u}(z)=\mathbf{P}\left(z, z_{0}\right) \mathbf{u}\left(z_{0}\right)+\sum_{i=1}^{m} \mathbf{P}\left(z, \gamma_{i}\right) \mathbf{b}\left(\gamma_{\imath}\right) \Delta \gamma_{\imath}
$$

with the propagator matrix

$$
\begin{aligned}
\mathbf{P}\left(z-z_{0}\right) & =\left[\begin{array}{cccc}
C & 0 & S / \eta^{*} & 0 \\
0 & C & 0 & S / \eta^{*} \\
\eta^{*} S & 0 & C & 0 \\
0 & \eta^{*} S & 0 & C
\end{array}\right] \\
& +L \Delta z\left[\begin{array}{cccc}
-S & -C & -C / \eta^{*} & -S / \eta^{*} \\
C & S & S / \eta^{*} & C / \eta^{*} \\
-\eta^{*} C & -\eta^{*} S & -S & -C \\
\eta^{*} S & \eta^{*} C & C & S
\end{array}\right]
\end{aligned}
$$

where $C=\cosh (k \Delta z), S=\sinh (k \Delta z)$, and $\Delta z=\left(z-z_{0}\right)$.

\section{Incorporation Into Relaxation Method}

Although the propagator gives us an analytic solution for the flow field, this solution is difficult to evaluate at high wavenumbers. For a fixed $\Delta z$, differences between 
$\cosh (k \Delta z)$ and $\sinh (k \Delta z)$ become vanishingly small with large values of $k_{n}$, and the propagator becomes singular. Because our boundary conditions are split between the surface $(z=0)$ and the bottom $(z=1)$ of the fluid, a solution for the complete set of boundary conditions requires that we propagate from $z=0$ to $z=1$. As we thus cannot set $\Delta z$ to an arbitrarily small value, a straightforward evaluation of the solution is intractable.

To overcome this difficulty, we combine the propagator with a numerical finite difference algorithm to evaluate the solution. The technique we use resembles a standard relaxation scheme for solving two-point boundary value problems. Such methods are stable, ideally suited to problems in which the solution contains dying and growing exponentials (such as appear in our hyperbolic sines and cosines) and are efficient in memory use when performed on a digital computer. Additionally, relaxation methods are well-developed, and fast, standardized routines have been developed for their application. We therefore use a standard relaxation code [Press et al., 1986] but alter it to incorporate the propagator.

In a conventional finite difference method, we essentially replace the differential equation

$$
\frac{d \mathbf{u}}{d z}=\mathbf{A u}
$$

with the finite difference equation

$$
\frac{\Delta \mathbf{u}}{\Delta z}=\mathbf{A u}
$$

or,

$$
\Delta \mathbf{u}=\mathbf{A} \mathbf{u} \Delta z
$$

Starting at a known value of $\mathbf{u}$ (e.g., at the boundaries), we may then use equation (A12) to find successive values of $\mathbf{u}$ at discrete grid points. Such a solution is dependent upon on the spacing between grid points $\Delta z$, with an increasing degree of error associated with increasing values of $\Delta z$. The standard relaxation method attempts to minimize these errors and distribute them evenly among the grid points through an iterative process of error correction; with each iteration, the solution at each grid point then relaxes toward a value in keeping with the finite difference equation and boundary conditions. A strength of this method is its stability, as errors are not allowed to grow over successive grid points. Drawbacks include the errors implicit in the finite difference approximation and the need for successive iterations to approach the solution.

By incorporating the propagator matrix $P$ into the relaxation scheme, we retain the stability advantages of the standard method but increase the accuracy and speed. As the propagator yields an exact expression for the change in $\mathbf{u}$ for a given $\Delta z$, we may rewrite equation (A8) as

$$
\Delta \mathbf{u}=\left(\frac{(\mathbf{P}-\mathbf{I})}{\Delta z}\right) \mathbf{u} \Delta z
$$

We see then that the finite difference matrix $\mathbf{A}$ in equation (A12) may be replaced by $((P-I) / \Delta z)$, a substitution that makes the equation exact and independent of grid spacing. The solution may then be obtained in a single iteration, and stability problems are avoided for the following reasons: with the relaxation code, the propagator is used only to relate the flow at adjacent grid levels, and it is no longer necessary to propagate from $z=0$ to $z=1$ to solve for the boundary conditions. We may therefore make $\Delta z$ arbitrarily small by increasing the number of grid levels, thereby keeping $\cosh (k \Delta z)$ and $\sinh (k \Delta z)$ small enough to avoid singularities at even high values of $k$. Any remaining numerical errors are then minimized by the error correction of the relaxation method and distributed throughout the grid. A further benefit of this method involves the vertical placement of density anomalies: because equation (A8) yields an exact expression for an anomaly's effect upon the flow at different depths, the depth resolution of the anomaly is independent of vertical grid spacing, and we may freely place density elements at intermediate depths between grid levels.

\section{Appendix D: Platelike Velocity Conditions}

To calculate the horizontal velocity at the top of the fluid, we use a method discussed by Hager and O'Connell [1981] and by Gable et al. [1991]. Surface velocities are platelike, and the dynamically consistent plate velocities are defined as those which add no energy to the system. To find the dynamically consistent plate velocities, we require that the forces acting upon each plate must sum to zero. The plate speed at which velocity-dependent and velocity-independent forces balance is then the desired velocity.

The forces which may act upon a lithospheric plate are varied; proposed force mechanisms include ridge-push, thermal thickening of the lithosphere, slab-pull, slab-resistance, collisional resistance, transform fault resistance, trench suction, and mantle drag [Forsyth and Uyeda, 1975; Hager and O'Connell, 1981]. In our model, only mantle drag and a form of slab-pull/trench suction appear. These forces are not parametrized in the fashion of force balance studies [Forsyth and Uyeda, 1975]; instead, they are fluid dynamical forces arising from the sinking of density anomalies and the resulting shear coupling between plate and mantle. Propelling the plates is a slab-induced, velocity-independent force that depends upon the shape and size of the subducting slab. This slab-induced force differs from the conventional slabpull mechanism of Elsasser [1969], wherein subducting lithosphere acts as a stress guide directly coupling the descent of the slab to the horizontal motion of the subducting plate. As the slabs in our model are fluid and strengthless, there is no such mechanical coupling. Instead, the sinking of dense material generates a local circulation about the slab, which in turn drives plate motions through a coupling between lithosphere and mantle [Hager and O'Connell, 1981]. As such coupling does not distinguish between subducting and overriding plates, the resulting plate force is a form of both slab-pull and trench suction. Retarding the plates is mantle drag, which is produced by shearing between the plate and those portions of the mantle which are not strongly driven by the local slab circulation. We calculate this force directly from the flow field; in practice, however, its strength varies directly with plate speed and size.

Potentially important mechanisms that we have neglected include lithospheric thickening and collisional resistance; we omit these and others to avoid complexity. Thermal lithospheric thickening adds a driving force that depends largely upon the spreading history of the system prior to the beginning of the experiment; the effect of this mechanism may be approximated by adding a constant, arbitrary driving force to each plate. Collisional resistance, as well as other plateboundary forces, depends upon the rheologies and processes 
in effect at a particular plate boundary; its contribution is to add a poorly constrained retarding force to each plate. The combined effect of these various mechanisms is to add a force of unknown or arbitrary magnitude and sign to the force balance on each plate. Such an addition will have an impact on plate velocities and suggests a future course of study; for now we seek the simplest model and include only mantle drag and slab-induced forces.

To determine the force components on each plate, we note the linearity of the equations governing the flow and decompose the flow field into density-driven and traction-driven components. The former is the flow produced by density anomalies sinking beneath a stationary surface; the latter is the flow driven by surface plates moving over a homogeneous fluid. We first calculate the density-driven flow, then integrate the shear stress along the base of the lithosphere to determine the effective driving force $d_{i}$ on each plate $i$. We next calculate the flow field associated with the motion of a single plate $j$ at a velocity $v_{j}=1$, then determine, for each plate $i$, the integrated shear stress $T_{i j}$ caused by the motion of plate $j$. Repeating the process for each plate gives us a matrix $\mathbf{T}$, for which $T_{i j}$ is the force exerted on plate $i$ by the motion of plate $j$. The force balance requirement on each plate then gives the expression

$$
\mathbf{T} \cdot \mathbf{V}=-\mathbf{D}
$$

where $T$ is the matrix of $T_{i j}, V$ is the array of unknown plate velocities $v_{j}$, and $\mathbf{D}$ is the array of density-driven shear stresses $d_{2}$ that are to be matched. Solving this matrix equation yields the dynamically consistent plate velocities.

Acknowledgments. This work was supported by NSF grant EAR 8708477 and NASA grant NAG5-840. We are grateful to Bruce Buffett, Carl Gable, Richard Holme, and Joann Stock for critiquing our manuscript, and to Dennis Hayes for providing maps of the western Pacific. We especially thank B. H. Hager and an anonymous reviewer for their insightful suggestions concerning the observational implications of ablative subduction and for detailed comments regarding our experimental method. Their comments and suggestions have prompted a significant refining of the ablative model, a process in which J. Stock and Göran Ekström have been of great assistance.

\section{REFERENCES}

Addicott, W. O., and P. W. Richards, Plate-tectonic map of the Circum-Pacific Region, Northwest Quadrant, Am. Assoc. of Pet. Geol., Tulsa, Okla., 1981.

Anderson, R. N., Update of heat flow in the east and southeast Asian seas, in The Tectonic and Geologic Evolution of Southeast Asian Seas and Islands, Part 1, Geophys. Monogr. Ser., vol. 23, edited by D. E. Hayes, pp. 319326, AGU, Washington, D. C., 1980.

Barker, P., and I. A. Hill, Back-arc extension in the Scotia Sea, Philos. Trans. R. Soc. London, Ser. A, 271, 151$183,1981$.

Beccaluva, L., G. Macciotta, C. Savelli, G. Serri, and O. Zeda, Geochemistry and $\mathrm{K} / \mathrm{Ar}$ ages of volcanics dredged in the Philippine Sea (Mariana, Yap, and Palau trenches and Parece Vela Basin), in The Tectonic and Geologic Evolution of Southeast Asian Seas and Islands, Part 1, Geophys. Monogr. Ser., vol. 23, edited by D. E. Hayes, pp. 247-270, AGU, Washington, D. C., 1980.
Benioff, H., Orogenesis and deep crustal structure: Additional evidence from seismology, Geol. Soc. Am. Bull., 65, 385-400, 1954.

Bevis, M., The curvature of Wadati-Benioff zones and the torsional rigidity of subducting plates, Nature, $32352-53$, 1986.

Bloomer, S. H., Distribution and origin of igneous rocks From the landward slopes of the Marianas Trench: Implications for its structure and evolution, J. Geophys. Res., 88, B9, 7411-7428, 1983.

Bloomer, S. H., and J. W. Hawkins, Gabbroic and ultramafic rocks from the Mariana Trench: An island arc ophiolite, in The Tectonic and Geologic Evolution of Southeast Asian Seas and Islands, Part 2, Geophys. Monogr. Ser., vol. 27, edited by D. E. Hayes, pp. 294-317, AGU, Washington, D. C., 1980.

Bowin, C., and P. H. Reynolds, Radiometric ages From Ryukyu Arc region and an Ar-40/Ar-39 age from biotite dacite on Okinawa, Earth Planet. Sci. Lett., 27 , 363-370, 1975.

Cardwell, R. K., B. L. Isacks, and D. E. Karig, The spatial distribution of earthquakes, focal mechanism solutions, and subducted lithosphere in the Philippine and northeastern Indonesian islands, in The Tectonic and Geologic Evolution of Southeast Asian Seas and Islands, Part 1, Geophys. Monogr. Ser., vol. 23, edited by D. E. Hayes, pp. 1-35, AGU, Washington, D. C., 1980.

Carney, J. N., and A. MacFarlane, Geologic evidence bearing on the Miocene to recent structural evolution of the New Hebrides Arc, the evolution of the the India-Pacific plate boundaries, Tectonophysics, 87, 147-175, 1982.

Chandrasekhar, S., Hydrodynamic and Hydromagnetic Stability, pp. 9-75, Oxford University Press, New York, 1961.

Chase, C. G., Extension behind island arcs and motions relative to hot spots, J. Geophys. Res., 83(B11), 53855387, 1978.

Cox, A., and R. B. Hart, Plate Tectonics: How it Works, pp. 30-32, Blackwell Scientific Publications, Palo Alto, CA, 1986.

Creager, K. C., and T. H. Jordan, Slab penetration into the lower mantle beneath the Mariana and other island arcs of the Northwest Pacific, J. Geophys. Res., 91(B3), 3573-3589, 1986.

Cross, T. A., and R. H. Pilger Jr., Controls of subduction geometry, location of magmatic arcs, and tectonics of arc and back-arc regions, Geol. Soc. Am. Bull., 93, 545-562, 1982.

Davies, G. F., and J. N. Brune, regional and global fault slip rates from seismicity, Nature, 229 101-107, 1971.

Dickinson, W. R., Widths of modern arc-trench gaps proportional to past duration of igneous activity in associated magmatic arcs, J. Geophys. Res., 78(17), 33763389, 1973.

Divis, A. F., The petrology and tectonics of recent volcanism in the central Philippine Islands, in The Tectonic and Geologic Evolution of Southeast Asian Seas and Islands, Part 1, Geophys. Monogr. Ser., vol. 23, edited by D. E. Hayes, pp. 127-144, AGU, Washington, D. C., 1980.

Elsasser, W. M., Convection and stress propagation in the upper mantle, The Application of Modern Physics to the Earth and Planetary Interiors, edited by S. K. Runcorn, pp. 223-246, Wiley-Interscience, New York, 1969. 
Elsasser, W. M., Sea-floor spreading as thermal convection, J. Geophys. Res., 76(5), 1101-1111, 1971.

England, P. C., and D. P. McKenzie, A thin viscous sheet model for continental deformation, Geophys. J. R. Astron. Soc., 70, 295-321, 1982.

Fischer, K., T. H. Jordan, and K. Creager, Seismic constraints on the morphology of deep slabs, J. Geophys. Res., 93(B5), 4773-4783, 1988.

Forsyth, D. W., and S. Uyeda, On the relative importance of the driving forces of plate motions, Geophys. J.R. astron. Soc, 43, 163-200, 1975.

Fryer, P., et al., Introduction, Proc. Ocean Drill. Program, Initial Rep., 125, 5-14, 1990.

Gable, C. W., R. J. O'Connell, and B. J. Travis, Convection in three dimensions with surface plates: generation of . toroidal flow, J. Geophys. Res., 96(B5), 8391-8405, 1991.

Garfunkel, Z., C. A. Anderson, and G. Schubert, Mantle circulation and the lateral migration of subducted slabs, J. Geophys. Res., 91(B7), 7205-7223, 1986.

Giardini, D., and J. H. Woodhouse, Deep seismicity and modes of deformation in Tonga subduction zone, Nature, 505-509, 1984.

Giardini, D., and J. H. Woodhouse, Horizontal shear flow in the mantle beneath the Tonga Arc, Nature, 319 551-555, 1986.

Gilluly, J., Plate tectonics and magmatic evolution, Geol. Soc. Am. Bull. 82, 2383-2396, 1971.

Gurnis, M., and B. H. Hager, Controls on the structure of subducted slabs and the viscosity of the lower mantle, Nature, 335 317-321, 1988.

Hager, B. H., and R. J. O'Connell, Subduction zone dip angles and flow driven by plate motion, Tectonophysics, $50,111-133,1978$.

Hager, B. H., and R. J. O'Connell, A simple global model of plate dynamics and mantle convection, J. Geophys. Res., 86(B6), 4843-4867, 1981.

Hamburger, M. W., R. K. Cardwell, and B. L. Isacks, Seismotectonics of the northern Philippine Island Arc, The Tectonic and Geologic Evolution of Southeast Asian Seas and Islands, Part 2, Geophys. Monogr. Ser., vol. 27, edited by D. E. Hayes, pp. 1-22, AGU, Washington, D. C., 1980.

Hamilton, W., Tectonics of the Indonesian Region, U.S. Geol. Surv. Prof. Pap., 1078, 1979.

Hegarty, K. A., J. K. Weissel, and D. E. Hayes, Convergence at the Caroline-Pacific plate boundary: Collision and subduction, in The Tectonic and Geologic Evolution of Southeast Asian Seas and Islands, Part 2, Geophys. Monogr. Ser., vol. 27, edited by D. E. Hayes, pp. 349359, AGU, Washington, D. C., 1980.

Holmes, A., The machinery of continental drift: the search for a mechanism, in Principles of Physical Geology, pp. 505-509, Ronald Press, New York, 1944.

Hussong, D. M., and P. Fryer, Structure and tectonics of the Mariana Arc and Fore-arc: Drillsite selection surveys, Initial Rep. Deep Sea Drill. Proj., 60, 33-44, 1981.

Hussong, D. M., and J. B. Sinton, Seismicity associated with back arc crustal spreading in the Central Mariana Trough, in The Tectonic and Geologic Evolution of Southeast Asian Seas and Islands, Part 2, Geophys. Monogr. Ser., vol. 27, edited by D. E. Hayes, pp. 217235, AGU, Washington, D. C., 1980.

Hussong, D. M., and S. Uyeda, Tectonic processes and the history of the Mariana Arc: A synthesis of the results of Deep Sea Drilling Project leg 60, Initial Rep. Deep Sea Drill. Proj., 60, 909-929, 1981.

Hussong, D. M. et al., Leg 60 ends in Guam, Geotimes, $12,19-22,1978$.

Hussong, D. M., S. Uyeda, R. Knapp, H. Ellis, S. Kling, and J. Natland, Deep Sea Drilling Project leg 60: Cruise objectives, principal results, and explanatory notes, Initial Rep. Deep Sea Drill. Proj., 60, 3-30, 1981.

Hyndman, R. D., Plate motions relative to the deep mantle and the development of subduction zones, Nature, 238 263- 265, 1972.

Isacks, B. L., Uplift of the Central Andean Plateau and bending of the Bolivian Orocline, J. Geophys. Res., 93(B4), 3211-3231, 1988.

Isacks, B., and M. Baraganzi, Geometry of Benioff Zones: Lateral segmentation and downwards bending of the subducted lithosphere, in Island Arcs, Deep Sea Trenches and Back-Arc Basins, Maurice Ewing Ser., vol. 1, 99-114, edited by M. Talwani and W. C. Pitman III, pp. 99-114, Washington D. C., 1977.

Isacks, B., and P. Molnar, Mantle earthquake mechanisms and the sinking of the lithosphere, Nature, 223 11211124, 1969.

Isacks, B., and P. Molnar, Distribution of stresses in the descending lithosphere from a global survey of focalmechanism solutions of mantle earthquakes, Rev. Geophys., 9(1), 103-174, 1971.

Isacks, B., J. Oliver, and L. R. Sykes, Seismology and the new global tectonics, J. Geophys. Res., 73, 5855-5899, 1968.

Jacobsen, S. B., Isotopic constraints on crustal growth and recycling, Earth Planet. Sci. Lett., 90, 315-329, 1988.

James, D. E., and J. A. Snoke, Seismic evidence for continuity of the deep slab beneath central and eastern Peru, J. Geophys. Res., 95(B4), 4989-5001, 1990.

Jarrard, R. D., Relations among subduction parameters, Rev. Geophys., 24(2), 217-284, 1986.

Jordan, T. H., Composition and development of the continental tectosphere, Nature, $274 \quad 544-548,1978$.

Karig, D. E., Remnant arcs, Geol. Soc. Am. Bull., 83, 10571068, 1972.

Karig, D. E., Temporal relationships between back arc basin formation and arc volcanism with special reference to the Philippine Sea, in The Tectonic and Geologic Evolution of Southeast Asian Seas and Islands, Part 2, Geophys. Monogr. Ser., vol. 27, edited by D. E. Hayes, pp. 318325, AGU, Washington, D. C., 1980.

Karig, D. E., and J. Mammerickx, Tectonic framework of the New Hebrides Island Arc, Mar. Geol., 12, 187-205, 1972.

Karig, D. E., and B. Ranken, Marine geology of the forearc region, southern Mariana Island Arc, in The Tectonic and Geologic Evolution of Southeast Asian Seas and Islands, Part 2, Geophys. Monogr. Ser., vol. 27, edited by D. E. Hayes, pp. 266-280, AGU, Washington, D. C., 1980.

Kincaid, C., and P. Olson, An experimental study of subduction and slab migration, J. Geophys. Res., 92(B13), 13,832-13,840, 1987.

Larue, D. K., Cross section through the Mona Passage: Arc massif extension between converging subduction zones, (abstract), Eos Trans. AGU, 70(89), 1300, 1989. 
Laitrille, S. L., and D. M. Hussong, Crustal structure across the Mariana Island Arc, in The Tectonic and Geologic Evolution of Southeast Asian Seas and Islands, Part 1, Geophys. Monogr. Ser., vol. 23, edited by D. E. Hayes, pp. 209-221, AGU, Washington, D. C., 1980.

Lewis, S. D., and D. E. Hayes, The tectonics of northward propagating subduction along eastern Luzon, Philippine Islands, in The Tectonic and Geologic Evolution of Southeast Asian Seas and Islands, Part 2, Geophys. Monogr. Ser., vol. 27, edited by D. E. Hayes, pp. 57-78, AGU, Washington, D. C., 1980.

Malkus, W. G. R., and G. Veronis, Finite amplitude cellular convection, J. Fluid Mech., 4, 225-260, 1958.

McKenzie, D. P., and W. J. Morgan, Evolution of triple junctions, Nature, 125-133, 1969.

McKenzie, D. P., and R. L. Parker, The North Pacific: An example of tectonics on a sphere, Nature, 216 12761280, 1967.

Meijer, A., Primitive arc volcanism and a boninite series: examples from western Pacific island arcs, in The Tectonic and Geologic Evolution of Southeast Asian Seas and Islands, Part 1, Geophys. Monogr. Ser., vol. 23, edited by D. E. Hayes, pp. 271-282, AGU, Washington, D. C., 1980.

Morgan, W. J., Rises, trenches, great faults, and crustal blocks, J. Geophys. Res., 73, 1959-1982, 1968.

Mrozowski, C. L., and D. E. Hayes, A seismic reflection study of faulting in the Mariana fore arc, in The Tectonic and Geologic Evolution of Southeast Asian Seas and Islands, Part 1, Geophys. Monogr. Ser., vol. 23, edited by D. E. Hayes, pp. 223-234, AGU, Washington, D. C., 1980.

Mukhopadhyay, M., and S. Dasgupta, Deep structure and tectonics of the Burmese Arc: Constraints from Earthquake and Gravity Data, Tectonophysics, 149, 299-322, 1988.

Olson, P., An experimental approach to thermal convection in a two-layered mantle, J. Geophys. Res., 89(B12), 11,293-11,301, 1984.

Page, R. W., and R. J. Ryburn, K/Ar ages and geological relations of intrusive rocks in New Britain, Pac. Geol., 12, 99-105, 1977.

Parsons, B., and D. McKenzie, Mantle convection and the thermal structure of the plates, J. Geophys. Res., 83(B9), 4485-4496, 1978.

Peterson, E. T., and T. Seno, Factors affecting seismic moment release rates in subduction zones, J. Geophys. Res., 89(B12), 10,233-10,248, 1984.

Press, W. H., B. P. Flannery, S. A. Teukolsky, and W. T. Vetterling, Numerical Recipes: The Art of Scientific Computing, pp. 578-614, Cambridge University Press, New York, 1986.

Rangin, C., et al., Seabeam survey at the southern end of the Manila Trench. Transition between subduction and collision processes, offshore Mindoro Island, Philippines, Tectonophysics, 146, 261-278, 1988.

Rasmussen, J., and E. Humphreys, Tomographic image of the Juan de Fuca plate beneath washington and western Oregon using teleseismic P-wave travel times, Geophys. Res. Lett., 15(12), 1417-1420, 1988.

Richards, M. A., and G. F. Davies, Component separation in sinking slabs: how likely?, (abstract), Eos Trans. $A G U$, $70(89), 1315,1989$.

Scott, R., and L. Kroenke, Evolution of back arc spreading and arc volcanism in the Philippine Sea: Interpretation of leg 59 DSDP results, in The Tectonic and Geologic Evolution of Southeast Asian Seas and Islands, Part 1, Geophys. Monogr. Ser., vol. 23, edited by D. E. Hayes, pp. 283-292, AGU, Washington, D. C., 1980.

Silver, E. A., R. McCaffrey, and R. B. Smith, Collision, rotation, and the initiation of subduction in the evolution of Sulawesi, Indonesia, J. Geophys. Res., 88(B11), 94079418, 1983.

Stern, C. R., Tectonic erosion along the western plate margin of South America: Its role in the genesis of some Andean magmas, (abstract), Eos Trans. AGU, 70(89), $1300,1989$.

Sykes, L. R., and R. C. Quittmeyer, Repeat times of great earthquakes along simple plate boundaries, in Earthquake Prediction: An International Review, Maurice Ewing Ser., vol. 4, edited by D. W. Simpson and P. G. Richards, pp. 217-247, AGU, Washington, D. C., 1981.

Taylor, B., and G. D. Karner, On the evolution of marginal basins, Revs. Geophys., 21(8), 1727-1741, 1983.

Uyeda, S., and H. Kanamori, Back-arc opening and the mode of subduction, J. Geophys. Res., 84(B3), 1049$1061,1979$.

Wdowinski, S., R. J. O'Connell, and England, P., A continuum model of continental deformation above subduction zones: Application to the Andes and the Aegean, J. Geophys. Res., 94(B8), 10,331-10,346, 1989.

Weissel, J. K., Magnetic lineations in marginal basins of the West Pacific, Philos. Trans. R. Soc. London, Ser. A, 300, 223-247, 1981.

Wilson, J. T., Continental drift, in Continents Adrift and Continents Aground, edited by J. T. Wilson, pp. 19-33, W. H. Freeman, New York, 1963.

Wilson, J. T., A new class of faults and their bearing on continental drift, Nature, 207 343-347, 1965.

Zhang, J., B. H. Hager, and A. Raefsky, A critical assessment of viscous models of trench topography and corner flow, Geophys. J. R. Astron. Soc., 83, 451-475, 1985.

R. J. O'Connell and W. Tao, Department of Earth and Planetary Sciences, 20 Oxford Street, Harvard University, Cambridge MA 02138.

(Received November 26 1990; revised August 26 1991; accepted September 18 1991.) 